\title{
The Mortality Effects of Changing Public Funding for Home Health Care: an Empirical Analysis of Medicare Home Health Care in the United States
}

\author{
C. Orsini ${ }^{1}$
}

\begin{abstract}
In light of population aging, it is important to understand whether limiting public in-kind transfers to the elderly affects elderly mortality. I focus on home health care - a popular in-kind transfer - and I exploit variation in the Medicare home health care reimbursement that arose in 1997 in the US to study whether cuts to government coverage of home health care affected elderly mortality. Under the identifying assumptions of the DID model, I find that the cuts affected total mortality for some men but not women, suggesting that changes in home health care can affect elderly mortality and differences in mortality between men and women. For men aged between 65 and 74, the Interim Payment System was associated with an increase in mortality equal to 0.6 percent, an effect in absolute value comparable to the mortality response to a one percentage point change in unemployment rates and within the range of other estimates of the impact of health insurance on elderly mortality.
\end{abstract}

Running title: The Mortality Effects of Changing Public Funding for Home Health Care

Conflict of interest statement: There is no conflict of interest.

JEL Classification: I1; H0

Keywords: Home Health Care; Elderly Mortality; Interim Payment System; Medicare

\footnotetext{
${ }^{1}$ Department of Economics, University of Sheffield, and Department of Health Policy, London School of Economics and Political Science, chrorsini@gmail.com.

I thank participants at the Empirical Reading Group of the Department of Social Policy at the LSE, Soohyung Lee, the editor Edward Norton and two anonymous referees for their constructive comments. All errors are my responsibility.
} 


\section{Introduction}

Population ageing around the world is placing increasing pressure on government budgets (Pilichowski, Arnould, and Turkisch, 2007), so it is becoming increasingly important to determine whether limiting public transfers to the elderly may affect their wellbeing. Given that health care represents a growing share of government spending around the world and that the elderly are primary recipients of health care, it is of particular interest to understand the impact of limiting health care services to the elderly. ${ }^{2}$

In this paper I study whether public cuts in home health care affect elderly mortality. Home health care is an in-kind transfer popular in many countries consisting of health care services provided in the patient's home. ${ }^{3}$ Cuts in home health care can in principle impact mortality because home health care services tend to include skilled nursing services provided to patients with serious conditions who may not receive the essential care they need should the service be cut. For example, for the United States in 1996, the year before the policy change studied here, 41 percent of home health care visits provided through the Medicare program were visits provided by skilled nurses, and patients admitted to home health care included those with serious conditions such as heart disease, cancer, cerebrovascular disease, diabetes, and chronic obstructive pulmonary disease.

\footnotetext{
${ }^{2}$ For example, public health expenditures as a percentage of the GDP for year 2014 (and for 2007 in parentheses) were 8.6 (7.8) for France, 9.2 (7.6) for Germany, 5.7 (6.5) for Spain, 6.9 (6.2) for the UK, and 7.9 (6.9) for the US. Data are from the OECD (accessed in January 2017): http://www.oecd.org/els/health-systems/health-data.htm. Additionally, for the US, expenditures by the Medicare program (as a percentage of the GDP) were 2.9 in 2007 and 3.3 in 2012, the latest year for which data are available from the Medicare and Medicaid Statistical Supplement (data accessed in January 2017): https://www.cms.gov/Research-Statistics-Data-and-Systems/Statistics-Trendsand-Reports/MedicareMedicaidStatSupp/2013.html.

${ }^{3}$ For instance, in 2014 expenditures on home health care as a percentage of public health expenditure were 2.1 in Germany, 3.7 in France, 0.8 in Spain, and 3 in the UK. For the US, expenditures on Medicare home health care as a percent of expenditure on the Medicare program were equal to 3.3 percent in 2012 (the most recent year for which data are available from the Medicare and Medicaid Statistical Supplement) and equal to 11.3 percent in 1996, the year before the policy change studied here (data for total expenditure on Medicare for 1996 are from the United States Government Printing Office, accessed in January 2017 https://www.gpo.gov/fdsys/pkg/CPRT106WPRT56395/html/CPRT-106WPRT56395.htm. Data for expenditures on Medicare home health care in 1996 are from the Medicaid and Medicare Statistical Supplement for year 1996).
} 
To study whether cuts in the provision of home health care can affect elderly mortality, I take advantage of a unique legislative change in the United States that modified government financing for Medicare home health care in the 1990s. ${ }^{4}$ The policy change created the Interim Payment System (IPS), which de facto generated time and state variation in cuts in government financing for Medicare home health care. Specifically, the IPS imposed a cap on the average reimbursement per patient that home health agencies (i.e. home health care providers) were entitled to receive when treating elderly Medicare patients. The cap was a blend of each home health agency's average per patient cost in 1994 and the average per patient cost of home health agencies in the agency's census division. ${ }^{5}$ Because the cap had a regional component, even states with similar pre-policy utilization potentially faced different restrictive reimbursement limits relative to the average utilization in their census division. For instance, home health agencies in Georgia and Oklahoma provided similar average amounts of care to their users before 1997, but the agencies in Georgia faced a more restrictive cap as a result of the 1997 change than did the agencies in Oklahoma because the regional average per patient cost in the South Atlantic census division prior to the law change was lower than the regional average in the West South Central census division. ${ }^{6}$ The imposition of an average per patient cap created the incentive for agencies not to treat patients with long-term care needs (McKnight 2004), and, in fact, McKnight (2006) finds that the decline in home health care visits was especially pronounced for those identified as the sickest Medicare beneficiaries. The reimbursement mechanism introduced by the policy change allows me to exploit variation across time and across states to estimate a reduced-form equation to study whether the cap affected elderly mortality. ${ }^{7}$ I conduct the analysis by gender and age as well as by gender and age group for five of the most important causes of death for the

\footnotetext{
${ }^{4}$ See Section 2 on Medicare home health care.

${ }^{5}$ A census division is a cluster of states. See https://www2.census.gov/geo/pdfs/mapsdata/maps/reference/us_regdiv.pdf.

${ }^{6}$ This example is taken from McKnight $(2004,2006)$.

${ }^{7}$ This strategy was proposed by McKnight when studying the impact of the cuts on home health care service provision $(2004,2006)$.
} 
elderly: diseases of the heart, malignant neoplasm, chronic obstructive pulmonary disease and allied conditions, cerebrovascular disease, and diabetes mellitus. I group the remaining causes of death into a residual category.

This paper is the first to study whether the imposition of limits on public reimbursement to home health care affected total elderly mortality using administrative microdata on the universe of deaths for the elderly of a country. I am also the first researcher to study whether the IPS affected elderly mortality by looking at subgroups defined by age, gender, and cause of death.

Specifically, this paper furthers previous literature that focused on other aspects of the IPS for home health care but whose main focus was not whether the IPS affected mortality. For instance, work by McKnight $(2006,2004)$ uses survey data from the Medicare Current Beneficiary Survey to look at the impact of the IPS on home health care utilization and out of pocket expenditures for home health, as well as the impact of the IPS on Body Mass Index, difficulty with stooping or kneeling, lifting 10 pounds, and walking 2-3 blocks. McKnight (2006) shows that the IPS did not significantly affect the health measures listed above, and in a footnote writes that mortality was not significantly affected by the IPS, although results are not reported. A possible explanation for McKnight's findings on mortality is the small sample size of the survey used. Here I further the analysis of whether the IPS affected mortality because I use administrative data on the universe of death for the elderly, overcoming the possible small sample size issues encountered in using survey data. I also conduct the analysis by gender, age bands and by cause of death, which has not been done before.

Previous research that has tangentially looked at the impact of the IPS on mortality also includes the paper by Huckfeldt et al. (2015), who study a subgroup of Medicare patients, namely those discharged from hospital for stroke, hip fracture, or lower extremity joint replacement, and therefore confine their analysis to those patients. Huckfeldt et al. (2015) focus mainly on the impact of Medicare home health care payment reforms on home health payments, costs, and 
admissions. Additionally, Huckfeldt et al. (2015) find that the IPS did not affect total mortality for their sample of patients. ${ }^{8}$ My focus differs from that of Huckfeldt et al. (2015) because I am interested in understanding whether the IPS affected total elderly mortality. I do so because the patients studied in Huckfeldt et al. (2015) are not all patients eligible to receive home health care. In fact, for example, for year 2000 (Department of Health and Human Services, 2001) data show that 48 percent of Medicare home health users had no previous hospitalizations, meaning that the IPS could have in principle affected mortality for a large group of people not considered in the sample Huckfeldt et al. (2015) focus on. ${ }^{9}$ Because the IPS caused a cream skimming of beneficiaries receiving Medicare home health care that altered the participation margin in Medicare home health care, it is not possible to look at the impact of the IPS on mortality conditional on receiving any home health care (as noted also by McKnight 2006 when looking at other outcomes). Here the data allow me to focus on whether the IPS affected mortality of elderly individuals who are at least 65 years of age. Under the identifying assumptions of my identification strategy, I find that the IPS was associated with an increase equal to 0.6 in the overall mortality rate for men aged between 65 and 74 . The magnitude of this effect is comparable in absolute value to mortality responses to a one percentage point change in the unemployment rates found in published work (Ruhm, 2000 and McInerney and Mellor, 2012 when looking at the same period studied in Ruhm, 2000) and within the range of estimates of the impact of insurance on mortality (see Section 4.1). In contrast, the IPS did not affect total mortality for older men, perhaps because older men tend to be more fragile, and the results here suggest there are decreasing marginal returns in terms of preventing mortality with home health care for patients

\footnotetext{
${ }^{8}$ Huckfeldt et al. (2015), exclusively focusing on Medicare patients discharged from hospital for stroke, hip fracture, or lower extremity joint replacement, study the impact of Medicare payment reform on home health payments, costs and admissions looking at the Perspective Payment System (the system implemented after the IPS) and the IPS. Here I, as other research (McKnight, 2006) has done, focus on the IPS because only the IPS (and not the PPS) generated geographic and time series variation in the intensity of treatment (treatment being the imposition of limits in reimbursement).

${ }^{9}$ Additionally, other papers have used the identification strategy first proposed by McKnight: Engelhardt and Greenhalgh-Stanley (2010), Golberstein et al. (2009), and Orsini (2010).
} 
who are particularly frail. I also find that the IPS did not affect total mortality for women. It is well known that men and women have different mortality (Sickles and Taubman, 1997), and the reasons behind such differences as well as the reasons behind changes in such differences over time are not clear. My findings contribute to filling a gap in our understanding of the causes of changes in differences in mortality by gender: cuts in the provision of public home health care are possible triggers of changes in differences in mortality by gender, at least when considering the time frame of about three years, as I consider here due to the time period for which the IPS was in place.

\section{Medicare Home Health Care and the IPS}

\subsection{Medicare Home Health Care}

Medicare was enacted by Congress in the United States in 1965 to meet the health insurance needs of the elderly and the disabled. During the time period considered in this paper, Medicare consisted of three parts: hospital insurance, known as Part A, a supplementary medical insurance, known as part B, and a third part, known as Part C, that expanded beneficiaries' options for participating in private-sector health care plans. Medicare Part A is provided automatically and free of charge to people 65 or older that are eligible to receive Social Security or Railroad Retirement Benefits. Until 1997, Medicare Part A covered inpatient hospital care, short-term skilled nursing facilities services, hospice care, and home health care. Since 1997, Medicare Part A has covered all home health care visits for individuals not enrolled in Part A. For individuals enrolled in Medicare Part B, Medicare part A covers the first 100 home health care visits that follow an inpatient stay, and Part B covers visits in excess to the limit imposed after the inpatient stay and visits that are needed without a previous inpatient stay. Medicare home care covers six health care services: skilled nursing, physical therapy, occupational therapy, speech therapy, medical social work, and home health aide. Services provided by skilled nurses have the potential to save lives given that a large fraction of home health care patients suffer from 
potentially lethal conditions such as, but not limited to, heart disease and cancer, and services performed by nurses at home may be crucial to save some patients' lives. Examples of skilled care include wound care for pressure sores or a surgical wound, intravenous or nutrition therapy, injections, monitoring serious illness and unstable health status, teaching about prescription drugs, monitoring medication adherence, and administering medications. ${ }^{10}$ Home health nurses not only provide direct care and teach the patient and his/her caregivers about care for the patient, but they also manage, observe, and evaluate the care needs of the patient.

Potentially, even visits by home health aides could save lives. This is because the law in place in the period under study requires that home health aides undergo training aimed at recognizing emergencies and knowledge of emergency procedures, meaning that if a home health aide is visiting and an emergency arises, he/she has some training to respond to it. ${ }^{11}$

In order to be eligible to receive Medicare home health care, Medicare beneficiaries need to be "home-bound" and in need of "intermittent" and "part-time" care. Such care can be substantial. In fact, Medicare defines part-time or "intermittent" care as the care needed or given on fewer than 7 days each week or less than 8 hours each day with some exceptions in special circumstances. Additionally, Medicare does not cover home health aide services unless patients

\footnotetext{
${ }^{10}$ See: https://www.medicare.gov/what-medicare-covers/home-health-care/home-health-care-what-is-it-what-toexpect.html and Department of Health and Human Services (2010), Montauk, 1998 and the Medicare Benefit Policy Manual - Home Health Services. For examples of services performed by skilled nurses, see https://www.cms.gov/Regulations-and-Guidance/Guidance/Manuals/downloads/bp102c07.pdf. For instance, there is a need for skilled nursing in those cases where there is a reasonable potential for change in a patient's condition because there was a reasonable potential for a complication or an acute episode. For example, consider the case of a patient with congestive heart failure who requires observation by skilled nursing personnel for signs of adverse effects resulting from newly prescribed medication, or cases in which a patient needs administration of medications that the patient herself, because of age and condition, would not be able to administer. Also, there are cases in which the administration of medications always requires skilled nursing, such as intravenous treatments.

${ }^{11}$ Code of Federal Regulations, Title 42, Chapter IV, Subchapter G, Part 484, Subpart A, Section 484.36. Additionally, the law states that the aide training program must address each of the following subject areas: communications skills, observation, reporting and documentation of patient status and the care or service furnished, reading and recording temperature, pulse, and respiration, basic infection control procedures, basic elements of body functioning and changes in body function that must be reported to an aide's supervisor, maintenance of a clean, safe, and healthy environment, recognizing emergencies and knowledge of emergency procedures, the physical, emotional, and developmental needs of and ways to work with the populations served by the home health agency, including the need for respect for the patient, his or her privacy and his or her property, appropriate and safe techniques in personal hygiene and grooming, safe transfer techniques and ambulation, normal range of motion and positioning, adequate nutrition and fluid intake, any other task that the home health agency may choose to have the home health aide perform.
} 
are also getting skilled care such as nursing care or physical therapy, occupational therapy, or speech-language pathology services from the home health agency. Table 1 shows that patients do receive a substantial amount of skilled care, which dropped considerably as a consequence of the IPS. $^{12}$

\subsection{The IPS}

The Balanced Budget Act (BBA) of 1997 changed reimbursement for Medicare home health care. The change introduced by the law involved two steps. First, from 1997 to 2000, an Interim Payment System (IPS) was established that put a cap on how much each home care agency would be reimbursed per patient per year (agencies were reimbursed on a cost basis before the IPS). The cap had two parts: 75 percent of the value was based on each agency's 1994 average per patient cost and 25 percent was based on the average per patient cost of the agency's census division (a cluster of neighbouring states). For newer agencies the cap was set equal to the national median per-patient cost. The second step started in October 2000, when the IPS was changed to the Prospective Payment System (PPS). As the rules of the PPS did not vary by state, they generated time series variation but did not generate state variation as did the IPS. Therefore, as previous research has done for other outcomes (for example, See McKnight, 2006), I concentrate here on studying the impact of the IPS on mortality.

The cap introduced by the IPS implied that even states with similar pre-policy utilization potentially faced different reimbursement limits depending on their utilization relative to the average utilization in their census division.

\footnotetext{
${ }^{12}$ Data are from the Health Care Financing Administration (1998 and 2001).
} 


\section{Data, Causes of Death, and Empirical Strategy}

\subsection{Sample and Data}

To construct mortality rates, I use population estimates (denominator) produced by The Survey of Epidemiology and End Results (SEER), data used in other recent papers studying mortality, ${ }^{13}$ and micro-level data on the universe of deaths from the Multiple Causes of Death files (for the numerator) from year 1993 until year 2000, totalling 13,804,156 deaths for individuals aged 65 or more. The data contain the International Classification of Disease (ICD) codes to identify specific causes of death (see Appendix 1 and the section 3.2 for more details). ${ }^{14}$

Because the IPS caused a cream skimming of beneficiaries receiving Medicare Home health care that altered the participation margin in Medicare home health care, it is not possible to look at the impact of the IPS on mortality conditional on receiving any home health care. Here the data allow me to focus on the impact of the IPS on the mortality of elderly individuals who are at least 65 years of age, a group for whom Medicare eligibility either directly or through the spouse is nearly universal (for example, 96.44 percent of elderly aged 65 or more are covered by Medicare, according to data from the Current Population Survey for year 1996). ${ }^{15}$

I conduct the analysis on elderly mortality by gender because it is well known that the most evident difference in health by gender is the differential mortality of men and women. ${ }^{16}$ Additionally, I provide estimates by age groups: I consider the elderly aged between 65 and 74,

\footnotetext{
${ }^{13}$ Coile et al., 2014; Stevens et al., 2015; McInerney and Mellor, 2012.

${ }^{14}$ Multiple Causes of Death data files provided by the CDC are commonly used to study mortality. See, for example, studies by Snyder and Evans (2006), Buckles et al. (2016), Evans and Moore (2011), and Evans and Moore (2012).

${ }^{15}$ The paper by Finkelstein and McKnight (2008) is another study that looks at the impact of the introduction of Medicare on elderly mortality.

${ }^{16}$ Brown, 2002; Case and Paxsons, 2005; Nathaanson, 1984; Zopf, 1992; Sickles and Taubman, 1997.
} 
those aged between 75 and 84 , and those aged 85 or older. ${ }^{17}$ Finally, I provide estimates by age and gender on several causes of death. I am not able to provide estimates on mortality by poverty level. Previous research (McKnight, 2004, 2006) has shown that the drop in home health care utilization as a consequence of the IPS was especially severe among patients with income below the poverty line. However, neither SEER data nor administrative microdata with death records have information on income (SEER provides data by age groups, gender, geographic area, and race), so I cannot provide estimates by socioeconomic status.

\subsection{Selected Causes of Death}

In principle, the decline in Medicare home health care could affect deaths due to many conditions because, to be eligible for Medicare home health care, a patient needs to be homebound and there are many health conditions that could make a patient homebound.

However, some causes of death are of special interest because they represent top causes of death for people aged 65 or older, so, given that many people die from those causes, it is especially important to understand whether imposing limits on reimbursement of home health care impacts deaths from those causes. I focus on the five top causes of deaths for individuals aged 65 or more: diseases of the heart, malignant neoplasm, chronic obstructive pulmonary disease and allied conditions, cerebrovascular disease, and diabetes mellitus. I group the remaining deaths into a residual category. Table 2 shows the causes of death selected here as a fraction of total deaths for men and women aged 65 or older.

Also, the selected causes of death are important to look at because data on the use of Medicare home health care (Health Care Financing Administration, various years) show that patients admitted to Medicare home health care are in large part admitted due to conditions that

\footnotetext{
${ }^{17}$ The subdivision is in line with the epidemiology of ageing that tends to divide the elderly into three categories: "young old", "old", and "old old"- those elderly whose age is, respectively, between 65 and 74, 75 and 84, and 85 or more (see, for instance, Zizza et al., 2009).
} 
either (1) are the causes of death ${ }^{18}$ I focus on here or (2) are conditions that are risk factors for those causes of death. Table 3 also shows that there was a large decline in the number of people receiving visits for every condition listed there. The number of visits per person for each condition also dramatically decreased after the IPS was implemented, making it possible that the IPS caused an increase in deaths for at least some of those conditions for some groups. However, it is difficult to predict accurately which cause of death a person will die from, because at any given point in time people are exposed to risks of death from various causes. For instance, Chiang (1991) writes that it is possible that in a study of cancer as a risk of death, some persons may die from other causes during the study period. Due to competing risks of death, it is possible, for instance, to observe an increase in mortality for some cause of death and a decrease in others, even when total mortality for a given group increases. Also, due to different stages of ageing and differences in mortality by gender, it is possible for the impact of the IPS on mortality and mortality by cause of death to be heterogeneous across age groups/gender/cause of death.

\footnotetext{
${ }^{18}$ For more information, please see Online Appendix 2. When presenting statistics or studying mortality by causes of death, it is common to group specific International Classification of Diseases (ICD) codes according to the World Health Organization (WHO) regulations. For example, the Centers for Disease Control and Prevention (CDC) commonly uses such groupings in presenting statistics on mortality (see, for example, the technical notes in the documents that accompany the mortality data provided by the Centers for Disease Control and Prevention), so I follow the literature here in grouping ICD codes for deaths according to the WHO convention. For instance, Table 3 shows aggregated data on conditions of admission to Medicare home health care for year 1996 (Health Care Financing Administration, 1998). Referring to Table 3, let us consider people admitted to home health care for "Diseases of the Circulatory System." The diagnosis (ICD codes) within the category "Diseases of the Circulatory System" include all diagnoses (ICD codes) that are also within the category of deaths for "Diseases of the Heart" and "Cerebrovascular Diseases" plus the diagnosis (ICD codes) of "Essential Hypertension," which is a major risk factor for deaths due to "Diseases of the Heart" and deaths due to "Cerebrovascular Diseases" (Meissner, 2016). Also, patients admitted to home health care for "neoplasms" include those people for whom the neoplasm may degenerate into "malignant neoplasms" to the point of causing the person's death, and malignant neoplasm is one of the causes of death I focus on here. Finally, people admitted to home health care with the admission diagnosis "Diseases of the respiratory system" are people that either already have "Chronic Obstructive Pulmonary Diseases and Allied Conditions", i.e. the ICD codes for people with Diseases of the Respiratory system include the codes "Chronic Obstructive Pulmonary Diseases and Allied Conditions," which can be fatal and which is one of the causes of death I focus on here, or people with diagnoses recorded in the ICD codes that can potentially lead to death for Chronic Obstructive Pulmonary Diseases and Allied Conditions.
} 


\subsection{Empirical Strategy}

\subsubsection{Cross State Variation in the Policy Change}

The IPS imposed a cap based on a blend of each home health agency cost in 1994 and the cost in the census division. Therefore, two agencies with the same cost in 1994 but in states within different census divisions with different utilization may have faced very different caps after the IPS. The reasoning applied to an agency in a state can be applied to the average of agencies in that state, which allows me (following McKnight, 2004, 2006) to construct a measure of restriction in reimbursement of Medicare home health care at the state level. Therefore, with similar increasing trends between 1994 and 1997, states where aggregate home health agencies have average per patient costs below the census division in 1994 face a reimbursement limit that is less restrictive than the limit faced by states where, on average, the average per patient cost in 1994 is above the average per patient cost in their census division.

McKnight $(2004,2006)$ constructs a measure that captures a cross-state component of the variation implied by the IPS with the main focus of identifying the impact of the IPS introduced in 1997 by the BBA on the number of Medicare home care visits received by Medicare beneficiaries. Here I use the same measure to study whether the IPS affected elderly mortality.

To create the variable used by McKnight $(2004,2006)$ to capture the cross-state variation in reimbursement, I need to use a measure of cost. Here I follow McKnight (2006) and identify the average number of visits per user as the most appropriate measure of cost to use. More formally, McKnight $(2004,2006)$ defines the following measure of restriction in reimbursement generosity:

$$
\text { Restrictiveness }_{\mathrm{sc}}=\overline{\mathrm{A}}_{\mathrm{S}^{-}} \overline{\mathrm{A}}_{\mathrm{C}}
$$

where $\bar{A}_{S}$ is the average number of Medicare home care visits per user in 1994 in state s, and $\bar{A}_{C}$ is the average number of Medicare home care visits per user in 1994 in state s's census division. 
The restrictiveness measure is between -40.9 (Kentucky) and 34.7 (Utah). In Figure 1 I plot yearly mortality rates for men and women of various ages for states in the top $25^{\text {th }}$ percentile of the Restrictiveness Measure ("Highly Restricted States") and for states in the bottom $75^{\text {th }}$ percentile of the Restrictiveness Measure (“Other States"). Figure 1 shows that while mortality trends were similar in the two different groups of states before the policy change, mortality rates diverged beginning around 1998, especially for men.

\subsubsection{Difference-in-Differences Specification}

Equation 2 presents the difference-in-differences strategy that compares changes in mortality rates in states that were more restricted by the IPS with changes in mortality rates in states that were less restricted by the IPS:

$$
H_{i j t}=\alpha_{t}+S_{j}+S_{j} t+\text { Post }_{t} \beta+\text { Post }_{t} * \text { Restrictiveness }_{s t} \gamma+u_{j t}+e_{i j t}(2)
$$

$H_{i j t}$ is the natural logarithm of the mortality rate for the group in cell i defined by age and gender (age 65-74, age 75-84, age 85 or more; male, female) in state j in year $\mathrm{t} ; \alpha_{t}$ and $S_{j}$ are year and state fixed effects, and $S_{j} t$ are state trends. ${ }^{19}$ Post $_{t}$ is a dummy equal to 1 for years 1998-2000 in which the IPS was in place (McKnight, 2006). Restrictiveness st $_{\text {captures state }}$ variation in the policy change; $u_{j t}$ are state unemployment rates, which, starting with Ruhm (2000), have been shown to be important determinants of mortality; $e_{i j t}$ is the error term. I

\footnotetext{
${ }^{19}$ I also have estimated models without state trends, and the point estimates of the variable Post*Restrictiveness with or without state trends are within each other's confidence intervals. For instance, for precise estimates for men 65 or more, the point estimates and standard errors with state trends are 0.02432 and 0.01153 , and those without state trends are 0.02434 and 0.01255 . For the group of women aged 65 or more, estimates are in both cases (with and without state trends) very imprecise and an order of magnitude lower than those for men. Estimate*100 of the variable Post*Restrictiveness in the specification without state trends on the sample of women aged 65 or more is 0.00386 , which is within the $95 \%$ confidence interval of the estimates with state trends, which is -0.03941 , 0.04174 . The estimate* 100 of the variable Post*Restrictiveness with state trends is 0.0016 , which is within the $95 \%$ confidence interval of the estimate without state trends, which is [-0.03651, 0.02879].
} 
cluster the standard errors at the state level (Bertrand, Duflo, Mullainathan, 2004). To test the plausibility of the identification strategy — requiring that, absent the IPS, trends in mortality rates would have been the same in more intensively treated states compared to less intensively treated states-I restrict my sample to years 1993-1997 and interact year effects with the Restrictiveness measure, conditioning on state and year fixed effects as well as state unemployment rates. I test the null hypothesis that the interactions of year dummies with the Restrictiveness measure are jointly 0. From this exercise I cannot reject that trends in mortality were the same for more and less restricted states in the pre-policy period (Online Appendix 1 section A.1.2 for more details). ${ }^{20}$

\subsubsection{Back of the Envelope Calculations}

We are interested in the number of deaths related to the IPS, also by cause(s) of death and age and gender groups. In this section I illustrate how I use estimates from $\gamma$ in Equation 2 to calculate how many deaths were related to the IPS for different demographic groups.

First, under the identifying assumptions of the DID model presented in the previous subsection, the estimate of $\gamma * 100$ gives the percent impact on mortality of living - during the post policy period - in a state that provided an additional one visit per user above the regional (census division) during the pre-policy period. Given that the census division portion of the IPS payment limit was $25 \%, \gamma * 100$ can be interpreted as the percent impact on the mortality rate of cutting reimbursements by 0.25 visits per Medicare beneficiary in the post policy period, so to recover the impact of cutting reimbursement of one visit, $\gamma * 100$ needs to be multiplied by 4 . Second, to determine the impact of the IPS on mortality, we need an estimate of the impact of the IPS on the number of home health care visits. One estimate by McKnight (2006) shows that the IPS was associated with a decline equal to 3.4 visits per Medicare beneficiary, so to

\footnotetext{
${ }^{20}$ Online Appendix 3 also carries out an analysis that divides states into different groups based on the value of the Restrictiveness measure. Also, I added graphs illustrating trends in mortality rates in Online Appendix 3.
} 
determine the impact on the elderly mortality rate of a decline in reimbursement of 3.4 visits per Medicare beneficiary, $\gamma * 100$ needs to be multiplied by 13.6

$$
\text { (i.e. } 3.4 * 4=13.6) .^{21}
$$

Next, I focus on the post policy period and, keeping population estimates from SEER for years 1998-2000 constant, I use death records for years 1998-2000 to calculate the actual deaths for years 1998-2000 for each group and cause of death. I call this number $M_{i j 98-00 a c t u a l}$. Also, I use the estimates from Equation 2 to conduct a counterfactual calculation of the number of deaths there would have been absent the policy change, and I call this number to be determined $M_{i j 98-00 n o I P S}$. Putting the steps together, I can calculate $M_{i j 98-00 n o I P S}$ as follows (Online Appendix 1, section A1.3):

$$
M_{i j 98-00 \text { no IPS }}(1+13.6 * \gamma)=M_{i j 98-00 a c t u a l}
$$

Finally, with the estimate of $M_{i j 98-00 n o ~ I P S}$ I can calculate the estimate of the number of deaths for a specific group and cause of death as the difference between $M_{i j 98-00 a c t u a l}$ and

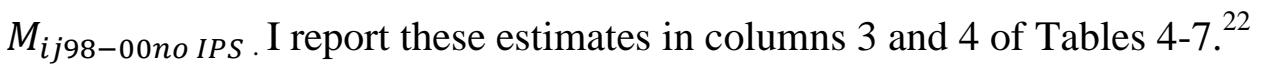

\section{Results}

\subsection{Results on Total Mortality By Age and Gender}

Under the identifying assumptions of the DID, results in the first row of Table 4 (columns 1 and 2, in curly brackets) show that the IPS was associated with an increase equal to 0.33 percent in the mortality rate for males at least 65 years of age. There is no significant effect

\footnotetext{
${ }^{21}$ The number 3.4 crucially relies on calculations made by the Health Care Financing Administration (HCFA) in 1999 on how many agencies were constrained by the policy and by how much these agencies were constrained (pages 305-306 and note 16), Health Care Financing Administration, 1999.

${ }^{22}$ Please see Online Appendix 4 for a calculation of the number of deaths "per reduced home health visit."
} 
of the IPS on total mortality rates for women of any group. Table 4 shows a precise estimate of the impact of the IPS on mortality rates for men aged between 65 and 74. For this group the IPS was associated with an increase in mortality equal to 0.618 percent. The size of the effect is in absolute value comparable to the mortality response to a one percentage point change in state unemployment rates as provided by Ruhm, 2000, and as validated for the same period by McInerney and Mellor, 2012. Given that the mechanism behind the relationship between unemployment rates and mortality is not clear, it is also relevant to compare my estimates to the range of estimates of the effect of the elderly's health insurance on mortality. Such estimates vary: in some studies, the estimates are null or very small (Finkelstein and McKnight, 2008; Kaestner et al., 2014), recent estimates of the impact of Medicare Part D on elderly mortality are around 2.2 percent (Huh and Reif, 2017), and other estimates are larger (Card et al., 2009; Sommers et al., 2014).

Table 4 also shows that the total mortality rate for elderly aged 75 or more was not significantly affected and there was never a significant effect on total mortality rates for women. I report below the results of my estimates by selected causes of death and elaborate on possible explanations for my findings in section $5 .^{23}$

\subsection{Results on Mortality from Specific Causes By Age and Gender}

When conducting an analysis of multiple outcomes, there is need to correct for multiple comparisons, to correct for the possibility that some precise results may simply be due to

\footnotetext{
${ }^{23}$ I also estimated Equation 2 on the group of people aged 25-34, a group which, when considered in its entirety, is unlikely to be much affected by the IPS due to the small fraction of people in that group enrolled in Medicare. Indeed, from my tabulations from the Behavioral Risk Factor Surveillance System in 1997, only 2.2 percent of people aged 25-34 are enrolled in Medicare (people younger than 65 can be enrolled in Medicare if they are disabled or have End of Stage Renal Disease). Although it is entirely possible that the IPS affected the mortality of the 2.2 percent of Medicare enrolees aged 25-34, due to the small fraction of people aged 25-34 with Medicare in the group of people aged between 25 and 34, I expect that my estimates of the effect of the IPS on mortality rates for the group of people between 25 and 34 years of age are very imprecise, which I find. In fact, the point estimates and standard errors multiplied by 100 of the variable Post*Restrictiveness from the model in Equation 2 estimated on the group of people aged between 25 and 34 are, respectively, 0.04906 and 0.06485 (with a P-value of 0.453 ) for men, and -0.01819 and 0.10175 (with a P-value of 0.853 ) for women.
} 
chance. A first method for doing so consists in the aggregation of outcomes in one or more groups. When using this approach, and when outcomes are different from each other, typically indexes are created (for example, see Kling, Liebman, and Katz, 2007). In the case of this paper, since all outcomes are mortality rates, the aggregation amounts to have total mortality rates as aggregate outcomes (as it is done here, see previous subsection).

Additionally, for the analysis by cause of death, p-values need to be adjusted to correct for multiple comparisons in order not to draw incorrect inferences. In this paper I use the FDR correction proposed by Benjamini, Krieger, and Yekuteli (2006). ${ }^{24}$ Given that mortality rates by cause are subcategories of total mortality rates by age group and gender, the groups over which the correction is applied are the ones defined by age bands and gender. This procedure allows the calculation of q-values, which have an interpretation analogous to p-values (as they effectively are FDR-adjusted p-values) and, within an FDR context, represent the smallest values at which the hypotheses under testing would be rejected. The p-values and the q-values are both reported in Table 5, Table 6, and Table 7. It is apparent that no q-value is below 0.10 , suggesting that it is not possible to pinpoint a specific precise change in mortality rates due to a cause of death as a consequence of the IPS.

\section{Discussion}

Results presented in the previous section show that estimates on total mortality rates of younger elderly men aged between 65 and 74 are precise, allowing me to conclude that the group of elderly men aged between 65 and 74 was adversely affected by the IPS, whereas there is no precise estimate on mortality for men aged between 75-84 and no precise estimate on total mortality rates for older elderly men. In this paper (as in the other papers looking at the impact of the IPS on other outcomes), I look at whether the IPS affected mortality rates for all

\footnotetext{
${ }^{24}$ Appendix 5 presents the steps to apply the procedure by Benjamini, Krieger, and Yekuteli (2006) in more detail. FDR offers a more balanced approach compared to, for example, a Bonferroni correction in the trade-off between correct and false rejections.
} 
people aged 65, and not all of them will be affected by the IPS because not all of them need Medicare home health care. This means that the average effect of the IPS needs to be strong "enough" to be detected with precision, and this precision will be low if there are heterogeneous effects within a subgroup. Therefore, given that here I have data for the entire population, when an estimate is imprecise, it does not mean that no subgroups of people may have been affected by the IPS; however, it may mean that the possible effect for the subgroup affected is not large enough to be detected with precision in the group of elderly under study.

However, it is of interest to try to understand why I find a precise estimate of the IPS on total mortality for elderly men aged between 65 and 74 but not for older men. A possible explanation is the existence of decreasing marginal returns in terms of preventing mortality with home health care the more fragile elderly men are. In the end, there is only so much that can be done to prevent death, and older elderly men, being more fragile, are more likely to die independent of the care received. In other words, these results suggest that for these men aged 75 or more, even before the IPS, home health care was unlikely to prevent deaths, and this may be the reason why the IPS, on average, was not associated with a change in total mortality for this group. Table 8 presents some evidence that older Medicare beneficiaries who used home care before the IPS tend to be more fragile compared to younger men aged 65-74. The table uses the Rand dataset of the Health and Retirement Study for years 1994 and 1996 and for the Asset and Health Dynamics of the Oldest Old for years 1993 and $1995 .{ }^{25}$ To construct the table, I focus on male Medicare beneficiaries who had used home care since the previous interview (the surveys do not ask whether respondents are currently using home health care) and who report having at least one limitation among the following: bathing, eating, dressing, walking across a room, and getting in or out of bed. These elderly, due to their limitations, are plausibly likely to be eligible for Medicare home health care. Table 8 suggests that men aged 75 or older who have at least

\footnotetext{
${ }^{25}$ Please see a description of the Rand HRS and AHEAD data at: http://www.rand.org/labor/aging/dataprod.html.
} 
one limitation and who used Medicare home health care since the previous interview tend to have a higher number of limitations compared to younger elderly aged between 65 and 74 (2.63 compared to 2.27 ; the difference is statistically significant). This finding suggests that it is plausible that death is more difficult to prevent for these older elderly men with home health care, compared to younger elderly men. This, in turn, makes it entirely possible that a decline in home health care services does not change total mortality for these men. ${ }^{26}$

My results suggest that the IPS did not significantly affect mortality rates for women. In general, mortality is the most obvious difference in health outcomes by gender (Sickles and Taubman, 1997), and it is very much an open question why such differences in mortality by gender exist and what may increase or decrease such differences. It is also important to highlight that the IPS was in place for only a relatively short period of time, and so results on mortality could have been the same if the policy had been in place longer. Nevertheless, these results show short-term effects of public cuts to home health care on mortality rates for men aged 65-74 but no precise effects on women, suggesting that changes in home health care financing may affect changes in differences in mortality by gender at least in the short run. The paper provides in the text and appendices a series of tests and robustness checks that the reader can inspect to form a view of how the IPS relates to mortality. As mentioned in section 3.3.2, under the identifying assumption of the DID model, these estimates represent the causal impact of the IPS on mortality, and estimates are precise when looking at total mortality for men aged 64-74. However, there are also some imprecise estimates, and data limitation do not allow further analysis along the lines of income, which was shown to be a relevant dimension to

\footnotetext{
${ }^{26}$ There is also evidence from the medical literature suggesting that older patients with a given condition are sicker the older they are. For example, Alhuwalia et al. (2011) report that older elderly Medicare beneficiaries with heart disease tend to have more comorbidities compared to younger elderly, and Piccirillo et al. (2008) show that the severity of comorbidities among cancer patients increases with age. Also, the older the person, the less the lungs function properly (Sharma and Goodwin, 2006), and the severity of chronic respiratory diseases tends to increase with age as a consequence (Jarad, 2011), leading to serious complications. This suggests that it is entirely possible that less could be done to save older patients compared to younger patients with home health care even before the IPS; therefore, it is plausible that the IPS did not significantly affect, on average, mortality rates for older Medicare patients.
} 
consider in previous work on the impact of IPS (for instance, see McKnight, 2006); therefore, to a more conservative eye, the estimates presented here may be seen as evidence of, if not a causal link, at least a relationship between the IPS and mortality.

Finally, this paper is not the only paper finding that changes in Medicare insurance precisely affect mortality for men but not for women. An example of another recent paper finding a precise impact on mortality rates for men but not for women is the paper on the impact of Medicare Part D on mortality rates by Huh and Reif (2017).

\section{Conclusion}

I exploit the time and state variation provided by a unique quasi-experiment generated by the IPS in the 1990s to study whether limiting public funding for home health care affects elderly mortality using administrative data on the universe of deaths of the elderly. My results suggest that the imposition of limits on reimbursement to public home health care can affect elderly mortality for some groups of elderly.

This finding that the IPS affected mortality for some elderly differs from findings on the impact of the IPS on mortality by previous research, which used survey data (McKnight, 2006) or focused on a subgroup of elderly Medicare beneficiaries (Huckfeldt et al., 2015), and did not find that the IPS affected mortality.

Additionally, these results showing that as a consequence of the IPS mortality for men and women changed differentially contribute to our understanding of triggers of changes in differences in mortality by gender. 


\section{References}

Ahluwalia, S.C., Gross, C.P., Chaudhry, S.I., Leo-Summers, L, Van Ness, P.H., Fred, T.R. 2011.Change in comorbidity prevalence with advancing age among persons with heart failure. Journal of General Internal Medicine 26: 1145

Anderson, M. 2008. Multiple Inference and Gender Differences in the Effects of Early Intervention: A Reevaluation of the Abecedarian, Perry Preschool, and Early Training Projects. 2008. Journal of the American Statistical Association. 103(484): pp. 1481-1495

Anderson RN, Miniño AM, Hoyert DL, Rosenberg HM. 2001. Comparability of Cause of Death Between ICD-9 and ICD-10: Preliminary Estimates. National Vital Statistics Reports. 49: $1-32$.

Brown, J. 2002. Differential Mortality and the Value of Individual Account Retirement Annuities. in M. Feldstein and J. Liebman, The Distributional Effects of Social Security Reform, University of Chicago Press: Chicago, IL, 2002

Benjamini, Y., Krieger, A., and Yekutieli, D. 2006. Adaptive Linear Step-Up Procedures That Control the False Discovery Rate. Biometrika, 93, 491-507.

Bertrand, M., Duflo, E., Mullainathan, S., 2004. How Much Should We Trust Difference in Differences Estimates. The Quarterly Journal of Economics 119, 249-275

Buckles, B. Hagemann, A., Malamud, O., Morrill, M., and Wozniak, A.2016.The Effect of College Education on Mortality. Journal of Health Economics, 50: 99-114.

Card, D., Dobkin, C., Maestas, N., 2009. Does Medicare save lives? Q. J. Econ. 124 (2),597636.

Case, Anne C. and Christina Paxson. "Sex Differences in Morbidity and Mortality." Demography 42, 2 (2005): 189-214. 
Chiang, C. L., 1991. Competing Risks in Mortality Analysis. Annual Review of Public Health, 12: $281-307$

Coile, C., P. B. Levine, R. McKnight.2014. Recessions, Older Workers, and Longevity: How Long Are Recessions Good for Your Health? American Economic Journal: Economic Policy 6(3): 92-119.

Department of Health and Human Services, Office of Inspector General. 2001. Home Health Community Beneficiaries 2001. October 2001

Department of Health and Human Services, Centers for Medicare \& Medicaid Services, 2010. Medicare Home Health Care

Engelhardt, G.V.,Greenhalgh-Stanley, N, 2010.Home Health Care and the Housing and Living Arrangements of the Elderly," Journal of Urban Economics 67:2 (March) 2010: 226238.

Evans, W. N. and Moore, T. 2012. Liquidity, Economic Activity, and Mortality Review of Economics and Statistics, 94(2): 400-418.

Evans, W. N. and Moore, T. 2011.The Short-Term Mortality Consequences of Income Receipt.Journal of Public Economics, 95(11-12): 1410-1424.

Finkelstein, A and McKnight, R. 2008 "What Did Medicare Do? The Initial Impact of Medicare on Mortality and Out of Pocket Medical Spending." Journal of Public Economics 92: 1644-1669.

Golberstein, E., Grabowski, D.C., Langa, K.M., and Chernew, M. 2009. Effect of Medicare Home Health Care Payment on Informal Care. Inquiry, 46(1): 58-71.

Health Care Financing Administration, 2000. Medicare and Home Health Care. Baltimore: Health Care Financing Administration Publication HCFA-10969 
Health Care Financing Administration (various years). Health Care Financing Review, Medicare and Medicaid Statistical Supplement. U.S. Government Printing Office, Washington, DC.

Health Care Financing Administration, 1999. Federal Register, U.S. Government Printing Office, Washington D.C: August 5

Huckfeldt, P. J., Sood, N., Escarce, J., J., Grabowski, D. C., Newhouse, J. P., 2014. Effects of Medicare payment reform: Evidence from the home health interim and prospective payment systems. Journal of Health Economics, E34(C): 1-18

Huh, J. and Reif, J . 2017. Did Medicare Part D Reduce Mortality? Journal of Health Economics, May, 53: 17-37

Jarad, N. 2011. Chronic obstructive pulmonary disease and old age?. Chronic Respiratory Disease, 8 (2): 143-151.

Kaestner, R., Long, C., Alexander, G.C., 2014. Effects of Prescription Drug Insurance on Hospitalization and Mortality: Evidence From Medicare Part D. NBER Working Paper \# 19948

Kling J.R., Liebman, J.B., and Katz, L. 2007. "Experimental Analysis of Neighborhood Effects," Econometrica, Econometric Society, vol. 75(1), pages 83-119, January

McInerney, M., and Mellor, J. M.2012. Recessions and Seniors' Health, Health Behaviours, and Healthcare Use: Analysis of the Medicare Current Beneficiary Survey. Journal of Health Economics, 31, 744-751

McKnight, R. 2004. Home Care Reimbursement, Long-Term Care Utilization, and Health Outcomes. NBER WP \# 10414

McKnight, R., 2006. Home Care Reimbursement, Long-Term Care Utilization, and Health Outcomes. Journal of Public Economics, 90(1):293-323. 
Meissner A. 2016. Hypertension and the Brain: A Risk Factor for More Than Heart Disease. Cerebrovascular Diseases Vol. 42, No. 3-4

Montauk, S., L. Home Health Care. American Family Physician. 1998 Nov 1; 58(7):16081614

Nathanson, C. A. (1984). Sex differences in mortality. Annual Review of Sociology, 191-213

Orsini, C. 2010. "Changing The Way The Elderly Live: Evidence From the Home Health Care Market In the United States” Journal of Public Economics, vol. 94(1-2), pages 142-152

Piccirillo, J.F., Vlahiotis, A., Barrett, L.B., Flood, K.L., Spitznagel, E.L., Steyerberg, E.W. The changing prevalence of comorbidity across the age spectrum. Critical Reviews in Oncology/Hematology. 2008;67(2):124-32.

Pilichowski E., Arnould E., and Turkisch E. Ageing and the Public Sector: Challenges for Financial and Human Resources, OECD Journal on Budgeting, 7 (4): 1-40.

Ruhm, C., 2000. Are Recessions Good For Your Health? .Quarterly Journal of Economics, 115( 2):617-650.

Sharma, G. and Goodwin, J. 2006. Effect of aging on respiratory system physiology and immunology. Clinical Interventions in Aging I (3): 253-260.

Sickles, R. C., \& P. Taubman, P. 1997. Mortality and morbidity among adults and the elderly. In M. R. Rosenzweig \& O. Stark (Eds.), Handbook of population and Family Economics Snyder, S. E., Evans, W. N., 2006. The impact of income on mortality: evidence from the Social Security notch. Review of Economics and Statistics 88 (3): 482-495

Sommers, B.D., Long, S.K., Baicker, K., 2014. Changes in mortality after Massachusetts health care reform: a quasi-experimental study. Ann. Intern.Med. 160 (9), 585-593.

Stevens, Ann H, Douglas L. Miller, Marianne E. Page and Mateusz Filipski. 2015. The Best of Times, the Worst of Times: Understanding Pro-cyclical Mortality. American Economic Journal: Economic Policy, 7(4): 279-311. 
Zizza, C. A., Ellison, K. J., Wernette, C. M. 2009. Total Water Intakes of Community-Living Middle-Old and Oldest-Old Adults. The Journals of Gerontology Series A: Biological Sciences and Medical Sciences. 64A (4): 481-486.

Zopf. P. 1992. Mortality Patterns and Trends in the United States. Greenwood: Westport, CT.

\section{FIGURES}

\section{Figure 1}

Panel A: Trends in Mortality Rates for Men 65+, 1993-2000

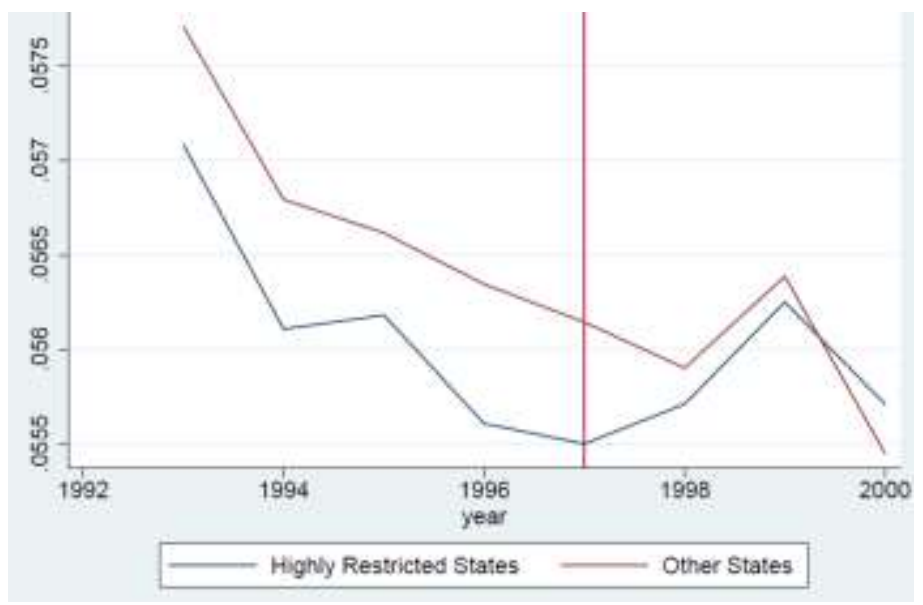

Panel B: Trends in Mortality Rates for Women 65+, 1993-2000

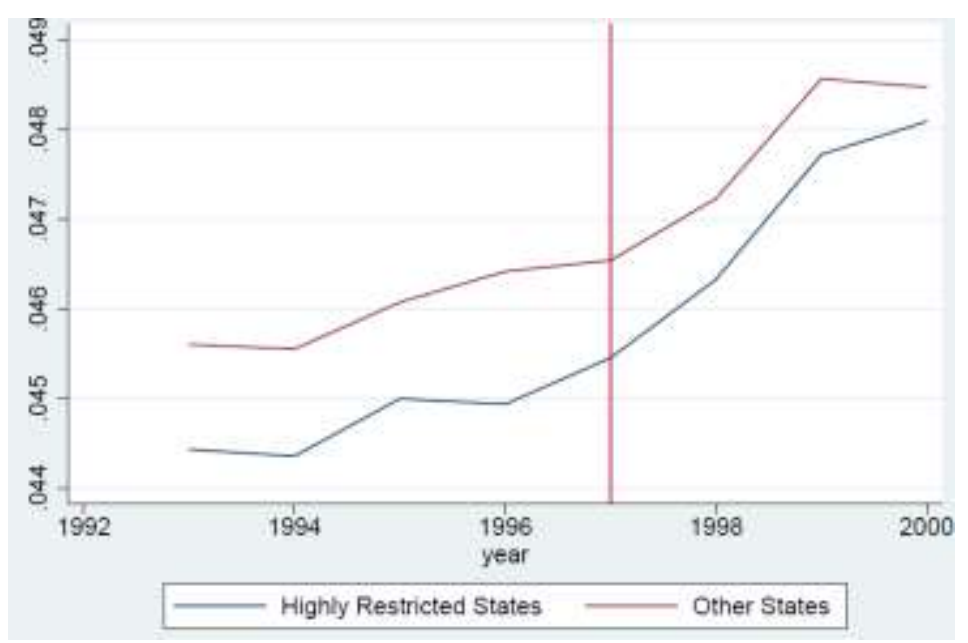

Note: the graphs above plot yearly mortality rates for men and women of various ages for states in the top $25^{\text {th }}$ percentile of the Restrictiveness Measure ("Highly Restricted States") and for states in the bottom $75^{\text {th }}$ percentile of the Restrictiveness Measure ("Other States"). 


\section{TABLES}

Table 1. Total Number of Medicare Home Health Care Visits

By Type of Service, 1996 and 1999

\begin{tabular}{lccc}
\hline $\begin{array}{c}\text { Number of Visits By } \\
\text { Type of Service }\end{array}$ & $\mathbf{1 9 9 6}$ & $\mathbf{1 9 9 9}$ & $\begin{array}{c}\text { Percent Drop in Visits } \\
\text { Between 1996 and 1999 }\end{array}$ \\
\hline Nursing Care & $108,839,000$ & $54,914,000$ & $49 \%$ \\
Home Health Aide & $129,502,000$ & $38,949,000$ & $70 \%$ \\
Physical Therapy & $19,320,000$ & $14,865,000$ & $23 \%$ \\
Speech Therapy & $1,292,000$ & 792,000 & $23 \%$ \\
Occupational Therapy & $3,142,000$ & $2,731,000$ & $13 \%$ \\
Medical Social Services & $2,704,000$ & $1,188,000$ & $57 \%$ \\
\hline \hline
\end{tabular}

Source: Health Care Financing Administration (1998 and 2001).

Table 2. Summary Statistics, Deaths By Cause, as a fraction of total deaths, Men and Women aged $65+$, Years 1993-2000

\begin{tabular}{lll}
\hline Cause of death & Men & Women \\
\hline $\begin{array}{ll}\text { Diseases of the heart } \\
\text { Malignant neoplasm }\end{array}$ & 0.3469 & 0.3560 \\
$\begin{array}{l}\text { Chronic obstructive pulmonary disease } \\
\text { and allied conditions }\end{array}$ & 0.2543 & 0.1947 \\
$\begin{array}{l}\text { Cerebrovascular disease } \\
\text { Diabetes mellitus }\end{array}$ & 0.0619 & 0.0490 \\
Remaining causes of death & 0.0248 & 0.0260 \\
Total Deaths & 0.2495 & 0.2823 \\
\hline
\end{tabular}

Note: Tabulations from Centers for Disease Control and Prevention (CDC) for years 1993-2000. Causes of death are grouped according to World Health Organization groupings followed also by the CDC. See Section 3 for more information. 
Table 3. Principal diagnosis of people admitted to Medicare Home Health Care, and number of Person Served and Visits Per Person, years 1996 and 1999

\begin{tabular}{|c|c|c|c|c|}
\hline \multirow[t]{2}{*}{$\begin{array}{l}\text { Principal Diagnosis of Persons } \\
\text { Using Medicare Home Health } \\
\text { Care }\end{array}$} & \multicolumn{2}{|c|}{$\begin{array}{l}\text { Number of Person Served (in } 000 \\
\text { and \% of total person served, in } \\
\text { parentheses) }\end{array}$} & \multicolumn{2}{|c|}{$\begin{array}{c}\text { Visits Per Person } \\
\text { Served }\end{array}$} \\
\hline & 1996 & 1999 & 1996 & 1999 \\
\hline Diseases of the Circulatory System & $\begin{array}{l}1059 \\
(29.4)\end{array}$ & $\begin{array}{l}855 \\
(31.4)\end{array}$ & 73 & 31 \\
\hline Neoplasms & $\begin{array}{l}232 \\
(6.4)\end{array}$ & $\begin{array}{l}190 \\
(7)\end{array}$ & 43 & 22 \\
\hline Diseases of the Respiratory System & $\begin{array}{l}289 \\
(8)\end{array}$ & $\begin{array}{l}315 \\
(11.6)\end{array}$ & 62 & 26 \\
\hline Diabetes Mellitus & $\begin{array}{l}257 \\
(7.1)\end{array}$ & $\begin{array}{l}172 \\
(6.3) \\
\end{array}$ & 131 & 67 \\
\hline
\end{tabular}

The diagnosis (ICD codes) within the category "Diseases of the Circulatory System" include all diagnoses (ICD codes) that are also within the category of deaths for "Diseases of the Heart" and "Cerebrovascular Diseases", which are two of the categories of causes of death studied here, plus the diagnosis (ICD codes) of "Essential Hypertension," which is a major risk factor deaths for "Diseases of the Heart" and deaths due to "Cerebrovascular Diseases" (see Appendix 2). People admitted to home health care with the admission diagnosis "Diseases of the Respiratory System" are people who either already have "Chronic Obstructive Pulmonary Diseases and Allied Conditions," which can be fatal, and is one of the categories of causes of death studied here, or are people with diagnosis that can lead to death for Chronic Obstructive Pulmonary Diseases and Allied Conditions (see Appendix 2). 
Table 4. Estimation Results, Impact of the IPS on Elderly Mortality, Various Groups

\begin{tabular}{|c|c|c|c|c|}
\hline & \multicolumn{2}{|c|}{ Estimates*100 } & \multicolumn{2}{|c|}{ Total Deaths from the Policy } \\
\hline & $\begin{array}{c}\text { Men } \\
(1)\end{array}$ & $\begin{array}{l}\text { Women } \\
\text { (2) }\end{array}$ & $\begin{array}{c}\text { Men } \\
\text { (3) }\end{array}$ & $\begin{array}{l}\text { Women } \\
\text { (4) }\end{array}$ \\
\hline 65 plus & $\begin{array}{l}0.02432 \\
(0.01153) \\
{[0.040]} \\
\{0.3307\}\end{array}$ & $\begin{array}{c}0.00116 \\
(0.0202) \\
{[0.954]} \\
\{0.0158\}\end{array}$ & 7914.71 & 465.24 \\
\hline $\begin{array}{l}\text { Mean of the mortality } \\
\text { rate }\end{array}$ & 0.05631 & 0.04659 & & \\
\hline $65-74$ & $\begin{array}{l}0.04551 \\
(0.02356) \\
{[0.059]} \\
\{0.6189\}\end{array}$ & $\begin{array}{l}0.00472 \\
(0.02352) \\
{[0.842]} \\
\{0.0642\}\end{array}$ & 4685.26 & 379.21 \\
\hline $\begin{array}{l}\text { Mean of the mortality } \\
\text { rate }\end{array}$ & 0.03186 & 0.01961 & & \\
\hline $75-84$ & $\begin{array}{l}0.000317 \\
(0.01487) \\
{[0.347]} \\
\{0.0043\}\end{array}$ & $\begin{array}{l}0.01533 \\
(0.02207) \\
{[0.491]} \\
\{0.2085\}\end{array}$ & 43.77 & 2216.39 \\
\hline $\begin{array}{l}\text { Mean of the mortality } \\
\text { rate }\end{array}$ & 0.07245 & 0.04799 & & \\
\hline 85 plus & $\begin{array}{l}0.03737 \\
(0.02853) \\
{[0.196]} \\
\{0.5082\}\end{array}$ & $\begin{array}{c}-0.01323 \\
(0.02759) \\
{[0.634]} \\
\{-0.1799\}\end{array}$ & 3154.26 & -2330.84 \\
\hline $\begin{array}{l}\text { Mean of the mortality } \\
\text { rate }\end{array}$ & 0.17675 & 0.14357 & & \\
\hline $\mathrm{N}$ & 408 & 408 & & \\
\hline
\end{tabular}

Columns 1 and 2 present estimates of $\gamma$ in Equation 2 in the main text multiplied per 100 and represent the percent change in mortality rates due to a decline of 0.25 visits per beneficiary. The percent effect of the IPS on mortality is in curly brackets. P-values of the estimates are in square brackets. Calculations in columns 3 and 4 use estimates in columns 1 and 2; see details in Section 3 and Appendix 1. Controls in every regression include state and year fixed effects, yearly state unemployment rate and state trends. 
Table 5. Estimation Results by Causes of Death, Elderly Aged 65-74

\begin{tabular}{|c|c|c|c|c|}
\hline & \multicolumn{2}{|c|}{ Estimates*100 } & \multicolumn{2}{|c|}{ Total Deaths from the policy } \\
\hline & $\begin{array}{l}\text { Men } \\
\text { (1) }\end{array}$ & $\begin{array}{l}\text { Women } \\
\text { (2) }\end{array}$ & $\begin{array}{l}\text { Men } \\
(3)\end{array}$ & $\begin{array}{l}\text { Women } \\
\text { (4) }\end{array}$ \\
\hline Diseases of the heart & $\begin{array}{c}0.04105 \\
(0.02394) \\
{[0.093]} \\
0.216 \\
\{0.5583\}\end{array}$ & $\begin{array}{c}0.06163 \\
(0.06972) \\
{[0.381]} \\
1 \\
\{0.8382\}\end{array}$ & 1298.88 & 1245.6 \\
\hline $\begin{array}{l}\text { Mean of the mortality } \\
\text { rate }\end{array}$ & 0.01036 & 0.00531 & & \\
\hline Malignant neoplasms & $\begin{array}{c}0.09211 \\
(0.04178) \\
{[0.032]} \\
0.216 \\
\{1.2527\}\end{array}$ & $\begin{array}{c}-0.0158 \\
(0.04618) \\
{[0.734]} \\
1 \\
\{-0.2149\}\end{array}$ & 3142.26 & -437.66 \\
\hline $\begin{array}{l}\text { Mean of the mortality } \\
\text { rate }\end{array}$ & 0.01058 & 0.00677 & & \\
\hline $\begin{array}{l}\text { Cerebrovascular } \\
\text { diseases }\end{array}$ & $\begin{array}{c}0.06514 \\
(0.08652) \\
{[0.455]} \\
0.295 \\
\{0.8859\}\end{array}$ & $\begin{array}{c}-0.19054 \\
(0.07849) \\
{[0.019]} \\
0.129 \\
\{-2.5913\}\end{array}$ & 292.29 & -861.50 \\
\hline $\begin{array}{l}\text { Mean of the mortality } \\
\text { rate }\end{array}$ & 0.00143 & 0.00109 & & \\
\hline $\begin{array}{l}\text { Chronic obstructive } \\
\text { pulmonary disease } \\
\text { and allied conditions }\end{array}$ & $\begin{array}{c}0.17517 \\
(0.09062) \\
{[0.059]} \\
0.216 \\
\{2.3823\}\end{array}$ & $\begin{array}{c}-0.00405 \\
(0.10439) \\
{[0.969]} \\
1 \\
\{-0.0551\}\end{array}$ & 1169.18 & -24.57 \\
\hline $\begin{array}{l}\text { Mean of the mortality } \\
\text { rate }\end{array}$ & 0.00199 & 0.00138 & & \\
\hline Diabetes mellitus & $\begin{array}{c}-0.10483 \\
(0.13473) \\
{[0.440]} \\
0.295 \\
\{-1.4257\}\end{array}$ & $\begin{array}{c}-0.03172 \\
(0.14671) \\
{[0.830]} \\
1 \\
\{-0.4314\}\end{array}$ & -356.73 & -110.07 \\
\hline $\begin{array}{l}\text { Mean of the mortality } \\
\text { rate }\end{array}$ & 0.00094 & 0.00082 & & \\
\hline $\begin{array}{l}\text { All remaining causes } \\
\text { of death }\end{array}$ & $\begin{array}{c}-0.06021 \\
(0.07306) \\
{[0.414]} \\
0.295 \\
\{-0.8189\}\end{array}$ & $\begin{array}{c}0.03981 \\
(0.05615) \\
{[0.482]} \\
1 \\
\{0.5414\}\end{array}$ & -1366.67 & 730.42 \\
\hline $\begin{array}{l}\text { Mean of the mortality } \\
\text { rate } \\
\mathrm{N}\end{array}$ & $\begin{array}{c}0.00656 \\
408\end{array}$ & 0.00423 & & \\
\hline
\end{tabular}

Columns 1 and 2 present estimates of $\gamma$ in Equation 2 in the main text multiplied per 100 and represent percent change in mortality rates due to a decline of 0.25 visits per beneficiary. The percent effect of the IPS on mortality is in curly brackets. P-values of the estimates are in square brackets. Q-values are in italics. Calculations in columns 3 and 4 use estimates in columns 1 and 2; see details in Section 3. Controls in every regression include state and year fixed effects, yearly state unemployment rate and state trends. 
Table 6. Estimation Results by Causes of Death, Elderly Aged 75-84

\begin{tabular}{|c|c|c|c|c|}
\hline & \multicolumn{2}{|c|}{ Estimates*100 } & \multicolumn{2}{|c|}{ Total Deaths from the policy } \\
\hline & $\begin{array}{c}\text { Men } \\
(1)\end{array}$ & $\begin{array}{l}\text { Women } \\
\text { (2) }\end{array}$ & $\begin{array}{l}\text { Men } \\
\text { (3) }\end{array}$ & $\begin{array}{l}\text { Women } \\
\text { (4) }\end{array}$ \\
\hline \multirow[t]{3}{*}{ Diseases of the heart } & $\begin{array}{l}0.02956 \\
(0.03289)\end{array}$ & $\begin{array}{l}0.01079 \\
(0.04017)\end{array}$ & \multirow[t]{4}{*}{1333.34} & \multirow[t]{4}{*}{490.40} \\
\hline & {$[0.373]$} & {$[0.789]$} & & \\
\hline & $\begin{array}{c}1 \\
\{0.40202\}\end{array}$ & $\begin{array}{c}1 \\
\{0.14674\}\end{array}$ & & \\
\hline $\begin{array}{l}\text { Mean of the mortality } \\
\text { rate }\end{array}$ & 0.02489 & 0.01616 & & \\
\hline \multirow[t]{3}{*}{ Malignant neoplasms } & $\begin{array}{l}0.01649 \\
(0.05973)\end{array}$ & $\begin{array}{l}-0.00203 \\
(0.04389)\end{array}$ & \multirow[t]{4}{*}{568.54} & \multirow[t]{4}{*}{-64.15} \\
\hline & {$[0.784]$} & {$[0.963]$} & & \\
\hline & $\begin{array}{c}1 \\
\{0.2243\}\end{array}$ & $\begin{array}{c}1 \\
\{-0.02761\}\end{array}$ & & \\
\hline $\begin{array}{l}\text { Mean of the mortality } \\
\text { rate }\end{array}$ & 0.01806 & 0.01043 & & \\
\hline \multirow[t]{3}{*}{$\begin{array}{l}\text { Cerebrovascular } \\
\text { diseases }\end{array}$} & $\begin{array}{l}-0.03327 \\
(0.10124)\end{array}$ & $\begin{array}{l}0.11442 \\
(0.07938)\end{array}$ & \multirow[t]{4}{*}{-289.69} & \multirow[t]{3}{*}{2342.62} \\
\hline & {$[0.744]$} & {$[0.156]$} & & \\
\hline & $\begin{array}{c}1 \\
\{-0.4525\}\end{array}$ & $\begin{array}{c}0.88 \\
\{1.5561\}\end{array}$ & & \\
\hline $\begin{array}{l}\text { Mean of the mortality } \\
\text { rate }\end{array}$ & 0.00481 & 0.00421 & & \\
\hline \multirow{4}{*}{$\begin{array}{l}\text { Chronic obstructive } \\
\text { pulmonary disease and } \\
\text { allied conditions }\end{array}$} & 0.06922 & $0.14527 *$ & \multirow[t]{5}{*}{661} & \multirow[t]{5}{*}{1336} \\
\hline & $(0.05473)$ & $(0.08366)$ & & \\
\hline & {$[0.212]$} & {$[0.089]$} & & \\
\hline & $\begin{array}{c}1 \\
\{-0.9414\}\end{array}$ & $\begin{array}{c}0.88 \\
\{1.9757\}\end{array}$ & & \\
\hline $\begin{array}{l}\text { Mean of the mortality } \\
\text { rate }\end{array}$ & 0.00488 & 0.00285 & & \\
\hline \multirow[t]{3}{*}{ Diabetes mellitus } & $\begin{array}{l}0.02307 \\
(0.15656)\end{array}$ & $\begin{array}{l}-0.00809 \\
(0.11197)\end{array}$ & \multirow[t]{4}{*}{88.24} & \multirow[t]{4}{*}{-39.93} \\
\hline & {$[0.883]$} & {$[0.943]$} & & \\
\hline & $\begin{array}{c}1 \\
\{0.3137\}\end{array}$ & $\begin{array}{c}0.88 \\
\{-0.1100\}\end{array}$ & & \\
\hline $\begin{array}{l}\text { Mean of the mortality } \\
\text { rate }\end{array}$ & 0.00183 & 0.00156 & & \\
\hline \multirow[t]{3}{*}{$\begin{array}{l}\text { All remaining causes } \\
\text { of death }\end{array}$} & $\begin{array}{l}-0.05446 \\
(0.05721)\end{array}$ & $\begin{array}{l}-0.02076 \\
(0.04488)\end{array}$ & \multirow[t]{5}{*}{-1980.63} & \multirow[t]{5}{*}{-860.49} \\
\hline & {$[0.346]$} & {$[0.646]$} & & \\
\hline & $\begin{array}{c}1 \\
\{-0.7406\}\end{array}$ & $\begin{array}{c}0.88 \\
\{-0.2823\}\end{array}$ & & \\
\hline $\begin{array}{l}\text { Mean of the mortality } \\
\text { rate }\end{array}$ & 0.01797 & 0.0128 & & \\
\hline $\mathrm{N}$ & 408 & 408 & & \\
\hline
\end{tabular}

Columns 1 and 2 present estimates of $\gamma$ in Equation 2 in the main text multiplied per 100 and represent percent change in mortality rates due to a decline of 0.25 visits per beneficiary. The percent effect of the IPS on mortality is in curly brackets P-values of the estimates are in square brackets. Q-values are in italics. Calculations in columns 3 and 4 use estimates in columns 1 and 2; see details in Section 3. Controls in every regression include state and year fixed effects, yearly state unemployment rate and state trends. 
Table 7. Estimation Results by Causes of Death, Elderly Aged 85 or Above

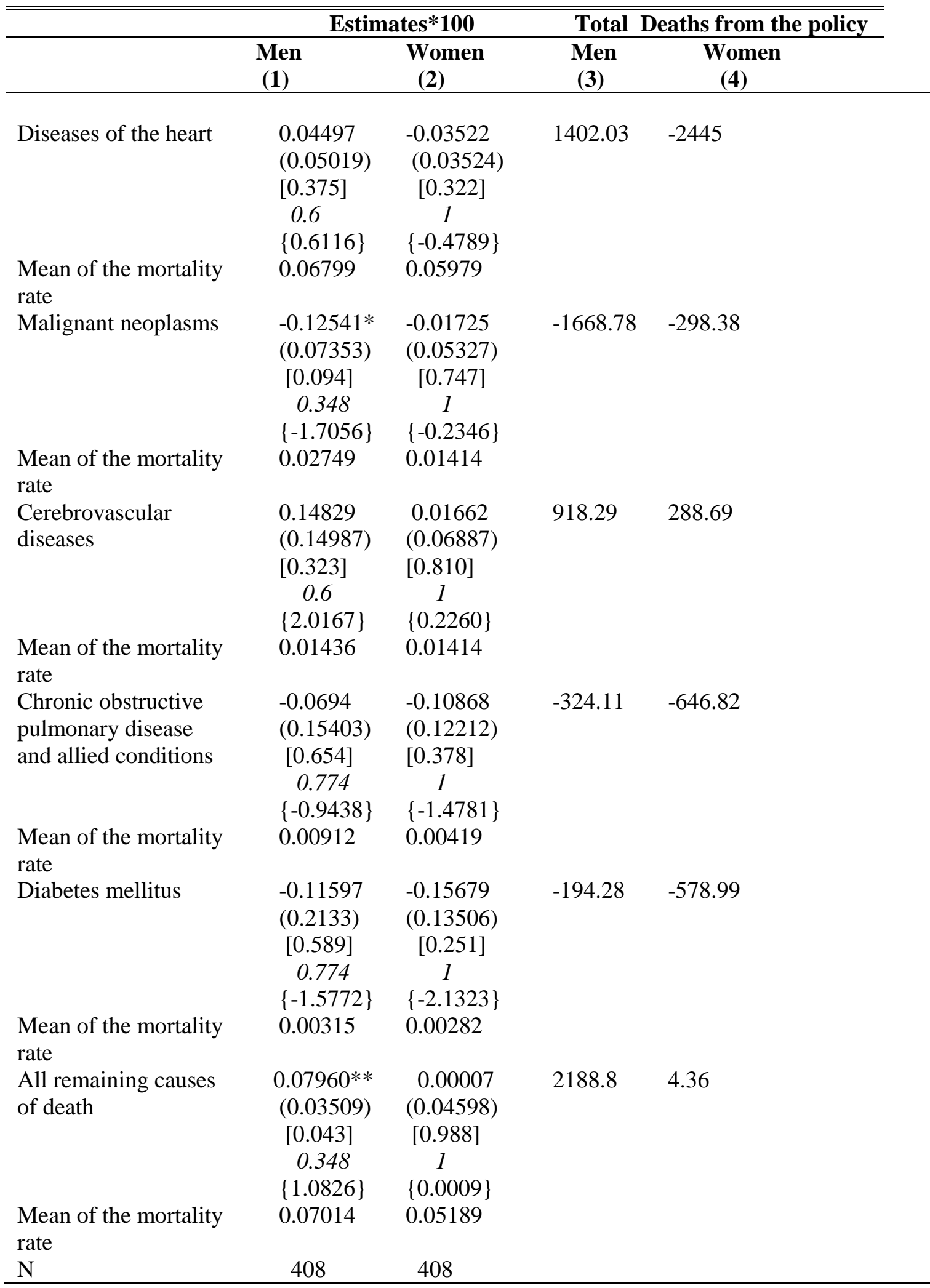

Columns 1 and 2 present estimates of $\gamma$ in Equation 2 in the main text multiplied per 100 and represent percent change in mortality rates due to a decline of 0.25 visits per beneficiary. The percent effect of the IPS on mortality is in curly brackets. P-values of the estimates are in square brackets. Q-values are in italics. Calculations in columns 3 and 4 use estimates in columns 1 and 2; see details in Section 3. Controls in every regression include state and year fixed effects, yearly state unemployment rate and state trends. 
Table 8. Number of Activity of Daily Living Limitations: Elderly Men aged 65 +, with at least one limitation, who used home health care since last interview

\begin{tabular}{|c|c|c|c|}
\hline & $65-74$ & 75 and older & $\begin{array}{l}\text { P-Value of the F-Test } \\
\text { Difference is significant }\end{array}$ \\
\hline $\begin{array}{l}\text { Total number of limitations } \\
\text { (Conditional on having any) } \\
\mathrm{N}\end{array}$ & $\begin{array}{l}2.2706 \\
(0.1901)\end{array}$ & $\begin{array}{l}2.6367 \\
(0.1008)\end{array}$ & 0.0899 \\
\hline \multicolumn{4}{|c|}{$\begin{array}{l}\text { Note: Data are from the sample of respondents in the Health and Retirement Study (HRS) for years } 1994 \text { and } \\
\text { 1996, and in the Assets and Health Dynamics of the Oldest Old (AHEAD) for years } 1993 \text { and } 1995 \text { as merged by } \\
\text { Rand (version P). The sample is composed of men aged } 65 \text { or more who report to have used home health care since } \\
\text { the last interview and who have at least one of the following limitations: bathing, eating, dressing, walking across a } \\
\text { room, and getting in or out of bed. Table } 5 \text { presents coefficients and standard errors of a regression with no } \\
\text { constant where the dependent variable is the number of limitations (conditional on having at least one) and the right } \\
\text { hand side variables are two dummies: a dummy equal to } 1 \text { if the respondent is an elderly man aged } 65-74 \text { and a } \\
\text { dummy equal to1 if the respondent is aged } 75 \text { or older. The regression is weighted using the individual weights. } \\
\text { The third column reports the P-value of the F-test of the null that the coefficient on the dummy equal to } 1 \text { if the } \\
\text { elderly men are aged between } 65 \text { and } 74 \text { is equal to the coefficient of the dummy that is equal to } 1 \text { if the elderly } \\
\text { men are aged } 75 \text { or older. }\end{array}$} \\
\hline
\end{tabular}

\section{Conflict of Interest Statement}

There are no conflicts of interest associated with the present paper. 


\section{ON-LINE APPENDIXES}

\section{Appendix 1}

\section{A1.1 Causes of Death}

I focus on 5 top causes of deaths for individuals aged 65 or more, namely deaths from: diseases of the heart, malignant neoplasm, chronic obstructive pulmonary disease and allied conditions, cerebrovascular disease, diabetes mellitus. I group the remaining deaths in a residual category. When presenting statistics or studying mortality by causes of death it is common to group specific International Classification of Diseases (ICD) codes according to the World Health Organization (WHO) regulations. For example, The Center For Disease Control and Prevention (CDC) commonly uses such grouping in presenting statistics on mortality (see, for example, the technical notes in the documents that accompany the mortality data provided by the $\mathrm{CDC}$ ), so I follow the literature here in grouping ICD codes for deaths according to the convention.

Causes of death in the period under study are coded according to two International Classification of Diseases codes (ICD), namely ICD-9 and ICD-10 codes. This means that my study spans more than one ICD classification, which is not uncommon when studying mortality (just as examples, other papers studying mortality in the US that span more than one ICD classification are the papers by Coile, Levine and McKnight, 2014 and the paper by Ruhm, 2000). To achieve comparability between the two classifications, the CDC estimates a comparability ratio calculated by dividing the number of deaths classified in the ICD-10 revision by the number of deaths classified in the ICD-9 revision. The comparability ratios represent the level of correspondence between the ICD-9 and ICD-10 codes for a given condition and a ratio of 1 indicates full comparability between the two codes for a given condition (Anderson et al., 2001). Column 4 of Table A1.1 which reports comparability ratios shows that comparability codes for all five conditions I focus on here are very close to 1 , 
suggesting a very high level of correspondence between the ICD-9 and ICD-10 codes for mortality for conditions studied here. Additionally, even if there are two ICD codes in the period of my study, the ICD classification affected at the same time classification of deaths in all US states, so its effect is accounted for by the year fixed effect in Equation 2 in the main text.

Table A1.1: Causes of Death and Comparability Ratios

\begin{tabular}{llll}
\hline Cause of death & ICD9-Code & ICD10-Code & $\begin{array}{l}\text { Comparability } \\
\text { Ratio }\end{array}$ \\
\hline Diseases of the heart & $\begin{array}{l}390-398, \\
402,404,410-429\end{array}$ & $\begin{array}{l}\text { I00-I09, I11,I13, I20- } \\
\text { I51 }\end{array}$ & 0.9858 \\
Malignant neoplasm & $140-208$ & C00-C97 & 1.0068 \\
$\begin{array}{l}\text { Chronic obstructive } \\
\text { pulmonary disease } \\
\text { and allied conditions }\end{array}$ & $490-496$ & J40-J47 & 1.0478 \\
$\begin{array}{l}\text { Cerebrovascular } \\
\text { disease }\end{array}$ & $430-434,436-438$ & I60-I69 & 1.0588 \\
Diabetes mellitus & 250 & & 1.0082 \\
\hline
\end{tabular}

Source: Anderson et al. (2001).

\section{A1.2. Plausibility of the Identification Assumption}

To test the plausibility of the identification strategy of the difference-in-differences specification in Equation 2 of the main text—requiring that, absent the IPS, trends in mortality rates would have been the same in more intensively treated states compared to less intensively treated states-I restrict my sample to years 1993-1997 and interact year effects with the Restrictiveness measure, conditioning on state and year fixed effects as well as state unemployment rates, and I test the null hypothesis that the interaction of year dummies with the Restrictiveness measure are jointly 0. Estimates are reported in Table A1.2 below. In no case it is possible to reject the null that coefficients of the interaction of year dummies with the Restrictiveness measure are jointly 0. 
Table A1.2: Testing the Identification Assumption

\begin{tabular}{lllll}
\hline \hline Panel A: Men & Men 65plus & Men 65-74 & Men 75-84 & Men 85+ \\
Year94*Restrictiveness & $5.93 \mathrm{e}-06$ & $-2.42 \mathrm{e}-06$ & -0.000043 & 0.000019 \\
& $(0.000159)$ & $(0.000288)$ & $(0.00018)$ & $(0.000415)$ \\
Year95*Restrictiveness & $-1.70 \mathrm{e}-06$ & 0.000016 & $6.98 \mathrm{e}-07$ & -0.000219 \\
& $(0.000150)$ & $(0.000236)$ & $(0.000203)$ & $(0.000305)$ \\
Year96*Restrictiveness & -0.000129 & -0.000095 & $1.57 \mathrm{e}-06$ & -0.000461 \\
& $(0.000159)$ & $(0.000285)$ & $(0.000181)$ & $(0.000312)$ \\
Year97*Restrictiveness & -0.000062 & -0.000126 & 0.000088 & -0.000253 \\
& $(0.000178)$ & $(0.000303)$ & $(0.000217)$ & $(0.000551)$ \\
N & 255 & 255 & 255 & 255 \\
P_Value of the F test for & 0.9133 & 0.9754 & 0.9753 & 0.5798 \\
the null: & & & & \\
Coefficients are jointly 0 & & & & \\
& & & & \\
Panel B: Women & Women & Women 65-74 & Women 75-84 & Women 85+ \\
& $\mathbf{6 5 p l u s}$ & & & \\
Year94*Restrictiveness & -0.000042 & $7.43 \mathrm{e}-06$ & -0.000310 & 0.000080 \\
& $(0.000165)$ & $(0.000213)$ & $(0.000263)$ & $(0.000242)$ \\
Year95*Restrictiveness & 0.000205 & 0.00006 & -0.000048 & 0.000397 \\
& $(0.000160)$ & $(0.000226)$ & $(0.000303)$ & $(0.000188)$ \\
Year96*Restrictiveness & -0.000036 & -0.000221 & -0.000179 & 0.000063 \\
Year97*Restrictiveness & $(0.000141)$ & $(0.000240)$ & $(0.000205)$ & $(0.000158)$ \\
& -0.000139 & -0.00016 & -0.000434 & 0.000015 \\
N & $(0.000219)$ & $(0.000277)$ & $(0.000353)$ & $(0.000211)$ \\
P_Value of the F test for & 255 & 255 & 255 & 255 \\
the null & 0.1289 & 0.5348 & 0.2177 & 0.2986 \\
Coefficients are jointly 0 & & & & \\
\hline & & & & \\
\hline
\end{tabular}

Note: Data restricted to years 1993-1997, omitted year is 1993, the outcome is mortality rate for a given group defined by age range and gender. I interact year effects with the Restrictiveness measure, conditioning on state and year fixed effects as well as state unemployment rates, and I test the null hypothesis that the interaction of year dummies with the Restrictiveness measure are jointly 0 .

I also provide graphs of estimates from an event study below. I have adopted the approach used by Hoynes, Miller, and Simon (2015) when studying the impact of OBRA 1993 on infant health. Specifically, after running the regressions with the event study, I have normalized the estimated coefficient for year 1997 interacted with the Restrictiveness measure to 0 and have plotted the coefficients in the graphs below for all groups studied in the paper. The graphs reveal that when looking at the combined group of men of men aged 65 or older and for the subgroup of men aged 65-74, there has been a sharp increase in mortality rates after 1997, 
whereas before the policy the pattern was different. For other subgroups of men, also it appears that years 1998-2000 were years of higher mortality rates, whereas in general the pattern for women seems more volatile.

\section{Figure A1.1 Event Study}
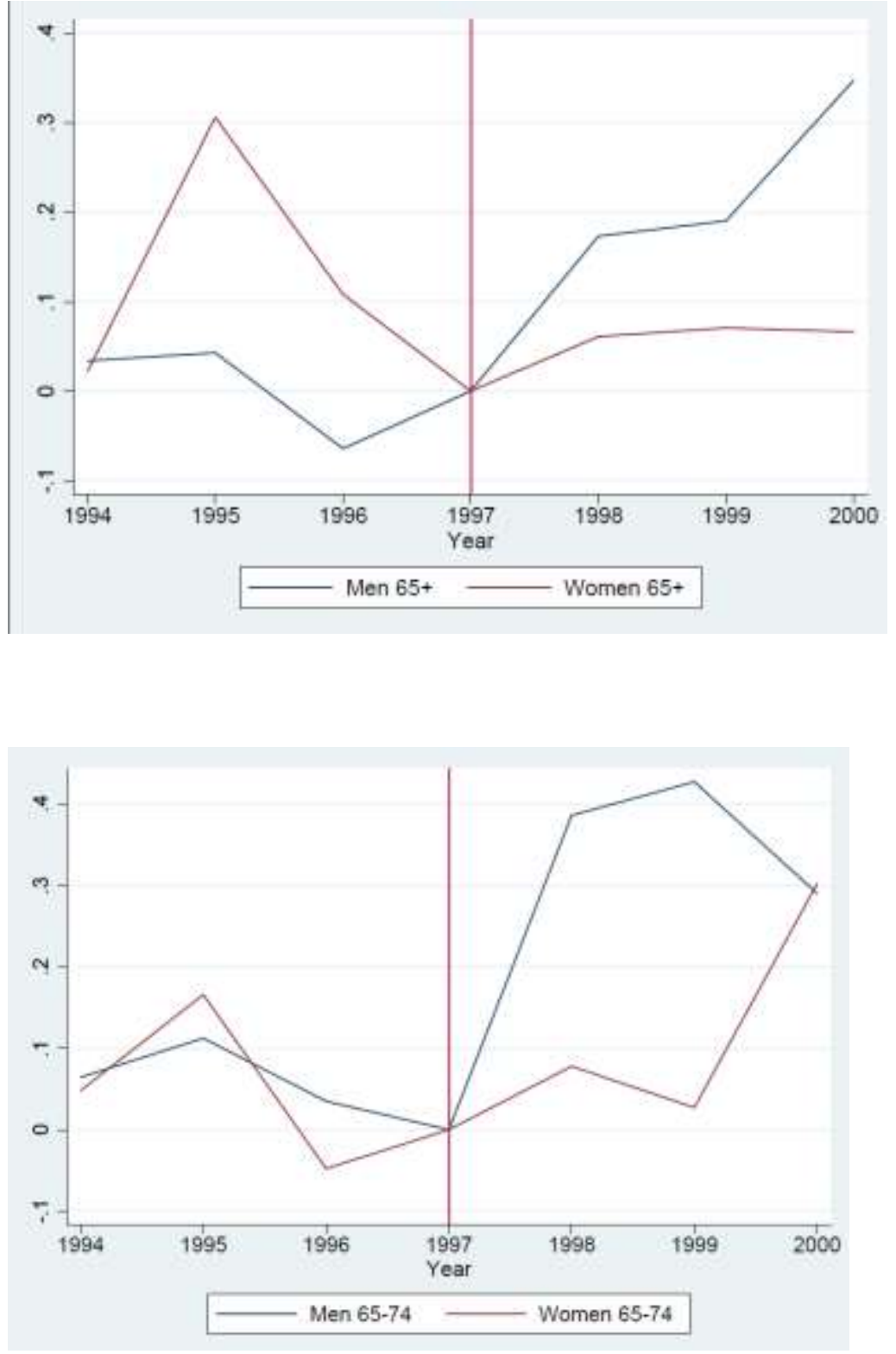

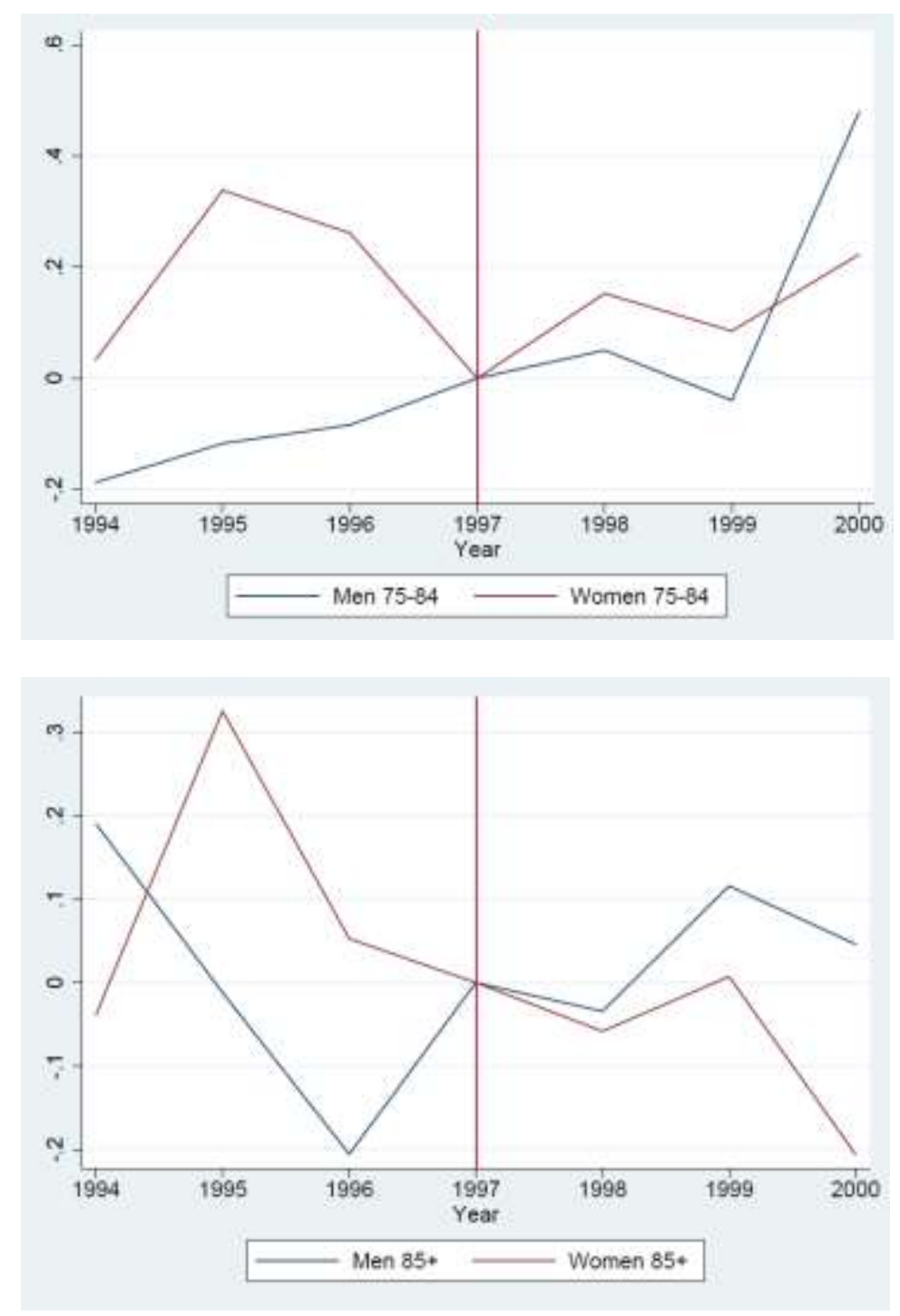

Notes: Each figure plots coefficients*1000 from an event-study analysis where the coefficients are year dummies interacted with the treatment indicator (the Restrictiveness Measure) and where the coefficient for year 1997 is normalized to 0 . The specification also includes year and state effects, as well as yearly state unemployment rates.

\section{A1.3 Calculation: Deaths due to the IPS}

As stated in the main text (Section 3.3.3), the parameter estimate of $\gamma$ multiplied by 100 gives the percent impact of cutting reimbursements by 0.25 visits per Medicare beneficiary in the post policy period on the mortality rate for elderly of a given gender and age. To translate this estimate of the impact of cutting a given number of visits per Medicare Beneficiaries on elderly mortality, we need an estimate of the impact of the IPS on the number of home health care visits. One estimate provided by McKnight (2006) is that the IPS caused a decline equal to 
3.4 visits per Medicare beneficiary, so to have the impact on the elderly mortality rate of a decline in reimbursement of 3.4 visits per Medicare beneficiary $\gamma$ needs to be multiplied by 13.6 ( i.e. $3.4 * 4=13.6$ ).

Below I use the estimates from equation 2 in the main text to provide a counterfactual calculation of the number of deaths there would have been absent the policy change. I call this number to be determined $M_{i j 98-00 n o I P S}$, and I call the actual number of deaths after the IPS $M_{i j 98-00 a c t u a l .}$

Also, I call the mortality rate that happened as a consequence of the IPS mortratepostips and call the mortality rate that would have happened absent the policy change mortratenoips. Using the estimate of $\gamma$ and the above information I have:

$\gamma * 100 * 13.6=\frac{\text { mortratepostips-mortratenoips }}{\text { mortratenoips }} * 100$

I can rearrange the above as:

mortratenoips $(\gamma * 13.6+1)=$ mortratepostips

I call the population of the relevant state, age, and gender group after the IPS Pop $p_{i j 98-00 n o ~ I P S}$ and I call the actual population after the IPS Pop $p_{i j 98-00 a c t u a l}$. Substituting in the equation above the mortality rates with the notation used for deaths and for population counts of the relevant group, the equation above can be rewritten as:

$\frac{M_{i j 98-00 \text { noIPS }}}{\text { Pop }_{i j 98-00 \text { noIPS }}}(\gamma * 13.6+1)=\frac{M_{i j a c t u a l}}{\text { Pop }_{\text {ijactual }}}$ since we have that $M_{i j 98-00 n o I P S}$ and Pop $p_{i j 98-00 n o I P S}$ are unknown, the equation above is not solvable. However, assuming that $P o p_{i j 98-00 n o I P S}=P o p_{i j a c t u a l}$, we have, as in the main text:

$M_{i j 98-00 n o ~ I P S}(1+13.6 * \gamma)=M_{i j 98-00 a c t u a l}$ 
Finally, with the estimate of $M_{i j 98-00 n o ~ I P S}$ in hand, I can calculate the estimate of the number of deaths for a specific group and cause of death as the difference between $M_{i j 98-00 a c t u a l}$ and $M_{i j 98-00 n o ~ I P S}$.

\section{Appendix 2. Causes of Death and Conditions for Admission in Medicare Home Health}

Care

In this Appendix I show that the ICD 9 of the causes of death I focus on here are among codes of top causes of admission to Medicare home health care. Additionally, among top conditions of admission to Medicare home health care there are also risk factors that can lead to causes of death studied in this paper, suggesting that a decline in home health care provision as a consequence of the IPS could have affected mortality for the causes of death I focus on in this paper. Table A2 uses aggregated data tabulated in the Medicare and Medicaid Statistical Supplement in 1996 (Health Care financing Review) to show top causes of admission in Medicare home health care. Statistics on aggregated ICD9 codes for admission to Medicare home health care are available in the Medicare and Medicaid Statistical Supplement of the Health Care Financing Review (Health Care Financing Administration, various years). ICD9 codes of conditions of admission in Medicare home health care in these data are aggregated differently from the way ICD 9 codes are aggregated when studying mortality according to the WHO convention. This difference in aggregation is perhaps not surprising: in fact, some conditions of admission are not causes of death per se; rather, they are risk factors for causes of death. For instance, in 1996, before the implementation of the IPS 29.9 percent of patients were admitted to Medicare home health care for "Diseases of the Circulatory System"; 6.4 percent were admitted for "Neoplasms"; 8 percent were admitted for "Diseases of the Respiratory System"; and 7.1 percent were admitted for Diabetes Mellitus. From Table A2 it is apparent that leading conditions for admission in Medicare home health care include the ICD 9 codes for the causes of death I study here and also include admissions in Medicare home health care for 
conditions that are risk factors for causes of death I study here. For instance, all ICD9 codes for deaths due to "Disease of the Heart" and deaths due to "Chronic Obstructive Pulmonary disease" are included in the codes for admission for home health care within "disease of the Circulatory System" which account for the highest fraction of admission, (29 percent of people admitted to Medicare home health care are admitted for "Diseases of the Circulatory System"). Also "Disease of the Circulatory System" include other conditions, most noticeably "Essential Hypertension" (ICD9 code 401) that is not a major cause of death per se but that is a major risk factor for the cause of death "Disease of the Heart" and "Cerebrovascular Diseases" and that includes a high percentage of admission to Medicare home health care (29 percent of total people admitted in Medicare Home health care for year 1996 were admitted for "Diseases of the circulatory system" and 16.5 percent of those were admitted for essential hypertension) . Additionally, admissions to Medicare home health care for "Neoplasm" (which in 1996 accounted for 6.4 of total patients admitted to Medicare home health care) may of course include those neoplasms that degenerate in malignant neoplasms one of the causes of death I study here. In fact, all the ICD9 codes for "Malignant Neoplasms" are included in the codes of admission for Medicare Home Health care for "Neoplasms". Finally, people admitted to home health care with the admission diagnosis "Diseases of the respiratory system" (8.1 percent of patients admitted to Medicare home health care in 1996) are people that either already have "Chronic Obstructive Pulmonary Diseases and allied Conditions", i.e. the International Classifications of Disease codes for people with Diseases of the Respiratory system include the codes "Chronic Obstructive Pulmonary Diseases and allied Conditions" which can be fatal, and also include people with diagnoses (ICD codes) that can lead to death for Chronic Obstructive Pulmonary Diseases and allied Conditions. Information on health conditions (and respective ICD-9 codes) comes from Tabulations in the Medicare and Medicaid Statistical Supplement, Health Care Financing Administration (1996). The tabulations reported in the Medicare and 
Medicaid Statistical Supplement do not include all ICD 9 codes of admissions, it only presents the top ones aggregated in broader categories that in total account for 61.9 percent of patients admitted to Medicare home health care. Conditions of admission that include the causes of death studied here account for 75.4 percent of the top conditions of admission for Medicare home health care in 1996. However, as highlighted in the main text (Section 3.2), it is ultimately difficult to predict accurately which cause of death a person will die from, because at any given point in time people are exposed to risks of death for various causes. For instance, Chiang (1991) writes that it is possible that in a study of cancer as a risk of death some persons may die for other causes during the study period.

Table A2. ICD 9 Codes for Causes of Death and Conditions of Admission to Medicare Home Health Care

\section{Panel A: Causes of ICD9 codes in Death}

Panel B: Conditions
of admission to
Medicare Home
Health Care

(3)

\author{
ICD9 codes in \\ conditions of \\ admission to \\ Medicare Home \\ Health Care
}

(4)

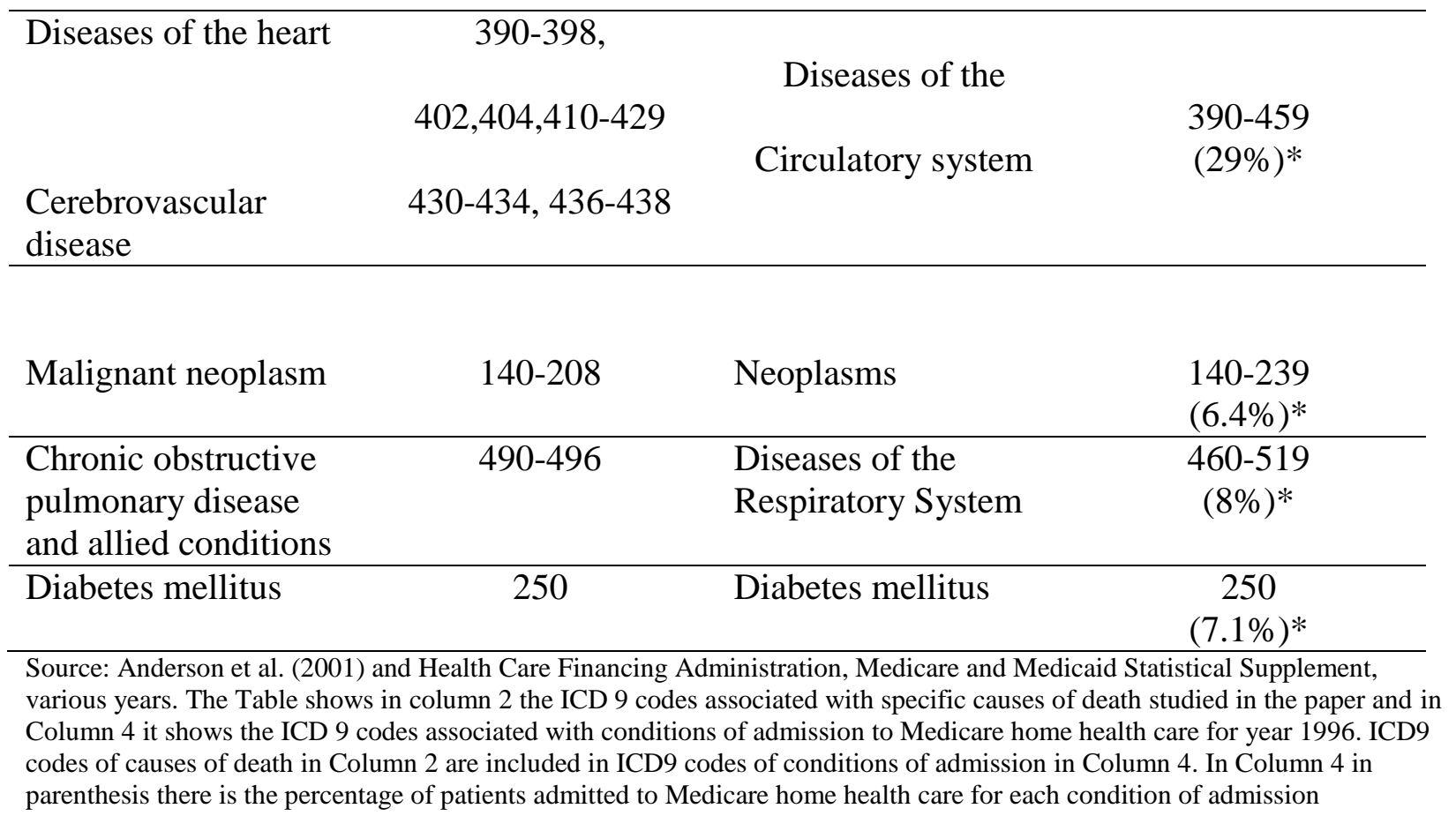




\section{Appendix 3. Other results}

It is worth checking whether the impact of the IPS is different at different points of the distribution of the Restrictiveness measure. To this end, I divided states in various groups using the two classifications below:

a) First classification: I divided states into 3 groups depending on whether they are in the bottom 33rd, medium 33rd, or top 33rd percentile of the distribution of values of the variable Restrictiveness. I then created three variables (called Restrictivenessfirst33,

Restrictivenesssecond33, Restrictivenessthird33) equal to their respective restrictiveness measures for the three groups of states. So, for instance, Restrictivenessthird33 has values between 0.4 and 34.7 and the other variables similarly capture other parts of the distribution.

b) Second classification: I have done a finer classification where I divided states into 4 groups depending on whether they are in the lowest 25th, second 25th, third 25th, or highest 25 percentile of the distribution of values of the variable Restrictiveness. I then created four variables (called Restrictivenessfirst25, Restrictivenesssecond25, Restrictivenessthird25, Restrictivenessfourth25) equal to the respective Restrictiveness measures for the four groups of states. So, for instance, Restrictivenessfourth 25 has values between 3.6 and 34.7 and the other variables similarly capture other parts of the distribution.

For both cases $\mathrm{a}$ and $\mathrm{b}$ above, I interacted the newly created variables with the post dummy. I then tested whether the coefficients on the newly created variables interacted with the Post dummy were statistically different from each other to test whether the impact of the IPS was different for different visit bands. For instance, for the classification for case $b$ above, I ran the following regression model (without a constant): 


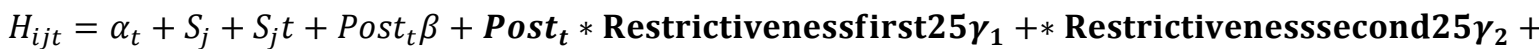

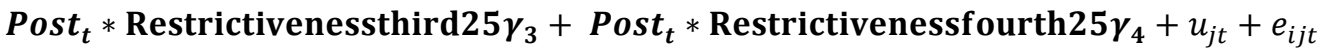

and tested whether the coefficients $\gamma_{1}, \gamma_{2}, \gamma_{3}, \gamma_{4}$ were pairwise equal to each other.

Then I did a similar exercise using the variables described in classification a above.

The results of these exercises are reported in Table A.3.1 below, which shows estimates of the variable Post interacted with the various Restrictiveness bands for men and women aged 65 or more. In both cases (using classification a as well as classification b above) and for both men and women, I could not reject the null that the coefficients on the post dummy interacted with the bands using different groupings of the Restrictiveness measure were equal to each other. However, it is also worth noting that when considering classifications a and b, the coefficient on the post dummy interacted with the highest values of the Restrictiveness measure: namely, Post interacted with Restrictivenessthird33 and Restrictivenessfourth25 was relatively more precisely estimated compared to estimates of Post interacted with the variables capturing other parts of the distribution of the Restrictiveness measure. For example, from Table A.3.1 below, for the group of men aged 65 or more, the point estimate of Post*Restrictivenesthird33 has a pvalue of 0.097 , whereas the p-values of the point estimates of Post*Restrictivenessfirst 33 and Post*Restrictivenesssecond 33 are 0.428 ad 0.889 , respectively. A similar point can be made when looking at the point estimates and p-values of the variables Post*Restrictivenessfirst25, Post*Restrictivenesssecond25, Post*Restrictivenessthird25, and Post*Restrictivenssfourth25. Because the higher the Restrictiveness measure, the more severe the cuts imposed by the IPS, these results suggests a stronger relationship between the Restrictiveness measure and mortality rates when on average states have home health care agencies facing relatively higher cuts. 
Table A3.1 Impact of the IPS on Mortality, Men And Women 65+

Estimates with Various Bands of the Restrictiveness Measure

\begin{tabular}{lcc}
\hline \hline & Estimates*100 & Women 65 or More \\
\hline $\begin{array}{l}\text { Panel A: } 3 \text { bands of the Restrictiveness } \\
\text { Measure }\end{array}$ & Men 65 or More & \\
\hline & & 0.00429 \\
Post*Restrictivenessfirst33 & 0.01626 & $(0.03053)$ \\
& {$[0.428]$} & {$[0.889]$} \\
Post* Restrictivenesssecond33 & -0.02431 & 0.05443 \\
& $(0.17314)$ & $(0.15947)$ \\
& {$[0.889]$} & $-0.734]$ \\
Post*Restrictivenesthird33 & 0.03787 & $(0.03978)$ \\
& $(0.02238)$ & $0.863]$ \\
P-value of the F-test of the null: estimate of & {$[0.097]$} & 0.7395 \\
the parameter of Post*Restrictivenessfirst33is & 0.8098 & \\
equal to the estimate of the parameter of & & \\
Restrictivenesssecond33*post & & 0.8494 \\
& & \\
P-value of the F-test of the null: estimate of & 0.5707 & \\
the parameter of Post*Restrictivenessfirst33 is & & \\
equal to the estimate of the parameter of & & \\
Post*Restrictivenessthird33 & & \\
& & \\
P-value of the F-test of the null: estimate of & 0.7303 \\
the parameter of Post*Restrictivenessfirst33 & & \\
is equal to the estimate of the parameter of & & \\
Post*Restrictivenessthird33 & & \\
\hline
\end{tabular}

Panel B: 4 bands of the Restrictiveness

Measure

Post*Restrictivenessfirst $25 *$ post

0.01795

0.00501

$(0.01761)$

$(0.02898)$

[0.313]

[0.863]

Post*Restrictivenesssecond25

$-0.05313$

$-0.05702$

$(0.11291)$

$(0.10056)$

[0.640]

[0.573]

Post*Restrictivenessthird25

0.06568

0.02137

$(0.15678)$

$(0.1132)$

[0.677]

[0.851]

Post*Restrictivenessfourth 25

0.04143

0.00433

$(0.02036)$

$(0.03833)$

[0.047]

[0.911]

P-value of the F-test of the null: estimate of

0.5277

0.5287

the parameter of Post*Restrictivenessfirst 25

is equal to the estimate of the parameter of 
Post*Restrictivenesssecond 25

P-value of the F-test of the null: estimate of

0.7582

0.8940

the parameter of Post*Restrictivenessfirst 25

is equal to the estimate of the parameter of

Post*Restrictivenesthird25

P-value of the F-test of the null: estimate of

0.4766

0.9897

the parameter of Post*Restrictivenessfirst 25

is equal to the estimate of the parameter of

Post*Restrictivenesfourth25

P-value of the F-test of the null: estimate of

0.5140

0.6402

the parameter of

Post*Restrictivenesssecond 25 is equal to the

estimate of the parameter of

Post*Restrictivenesthird25

P-value of the F-test of the null: estimate of

0.5896

the parameter of

Post*Restrictivenesssecond 25 is equal to the estimate of the parameter of

Post*Restrictivenessfourth25

P-value of the F-test of the null: estimate of

0.8827

0.8809

the parameter of Post*Restrictivenessthird 25

is equal to the estimate of the parameter of

Post*Restrictivenessfourth25

Note: estimates of equation 3.1 and a similar equation where instead of the variables Restrictivenessfirst25, Restrictivenesssecond25, Restrictivenessthird25, Restrictivenessfourth25, the variables Restrictivenessfirst33, Restrictivenesssecond33, Restrictivenessthird33 are used.

Based on the above results, I dichotomized the treatment: namely, I created a dummy that is equal to 1 if the state is in the top $25^{\text {th }}$ percentile of the Restrictiveness measure ("Top25\%") and interact such dummy with the post dummy. This variable measures the extent to which the impact of the IPS is larger in states in the top $25 \%$ of the values of the Restrictiveness measure compared to the other states. If I place Post $_{t} *$ Top 25thPercentile $_{\boldsymbol{s t}}$ in the outcome equation in the main text in section 3.3.1 instead of the Post*Restrictiveness variable, the resulting equation is as below:

$$
H_{i j t}=\alpha_{t}+S_{j}+S_{j} t+\text { Post }_{t} \beta+\text { Post }_{t} * \text { Top25thPercentile }_{s t} \gamma+u_{j t}+e_{i j t}
$$


Estimates of the equation above are reported in Table A.3.2 below. They show that as, a consequence of the IPS, mortality rates for men aged 65 or more increased 0.8 percent more in states in the top 25th percentile of the Restrictiveness measure compared to states in the bottom $75^{\text {th }}$ percentile of the Restrictiveness measure. This difference is statistically significant (the pvalue is equal to 0.038 ). For women, the point estimate is similar to the point estimate for men, but estimates are imprecise (the p-value is equal to 0.212 ). Other estimates in the table below can be similarly interpreted.

Table A3.2 Impact of the IPS on Elderly Mortality, Dichotomized Treatment

\begin{tabular}{lcc} 
& Men 65 or More & Women 65 or More \\
Post*Top25thpercentile & 0.0084618 & 0.0086269 \\
& $(0.0039655)$ & $(0.0068255)$ \\
P-value & 0.038 & 0.212 \\
\hline & Men 65-74 & Women 65-74 \\
Post*Top25thpercentile & 0.01566 & 0.01198 \\
& $(0.00633)$ & $(0.00778)$ \\
P-value & 0.017 & 0.130 \\
\hline & Men 75-84 & Women 75-84 \\
Post*Top25thpercentile & 0.00028 & 0.01076 \\
& 0.00541 & 0.00734 \\
P-value & 0.958 & 0.149 \\
\hline & Men $\mathbf{8 5}$ or More & 0.00677 \\
Post*Top25thpercentile & 0.01403 & 0.00671 \\
& 0.00844 & 0.318 \\
P-value & 0.103 & \\
\hline
\end{tabular}

Note: estimates of Equation A.3.2 above.

Since estimates of the impact of the IPS on mortality rates were more precise for states in the top $25^{\text {th }}$ percentile of the distribution of the Restrictiveness measure. Therefore, I divided states into two groups: "Highly Restricted States" (states in the top $25^{\text {th }}$ percentile of the Restrictiveness measure) and "Other States" and plotted mortality rates over time for men and women of different age groups. I report the figures below. For instance, for men aged 65 or more, Panel A of Figure A.3.1 displays that, in the period considered, mortality rates of men aged 65 or more declined in "Highly Restricted States" and "Other States" before the IPS. However, it is also apparent that after 1997 there was a sharp increase in mortality rates in 
"Highly Restricted States" that is more pronounced than the increase in mortality rates in "Other States." In 2000 mortality rates for "Other States" declined again, but they declined less in more restricted states. As it is apparent from the figures in McKnight's (2006) paper on the entire group of elderly 65 or older, the decline in Medicare home healthcare after the IPS was indeed most pronounced in years 1998 and 1999, so what happens to mortality rates is understandable in light of the trends in visits for the entire group of elderly 65 or older. For women aged 65 or more, Panel B of Figure A.3.1 shows that mortality rates for women 65 or older increased over time in "Highly Restricted States" and in "Other States." This increase seems to become a bit more pronounced for women in "Highly Restricted States" compared to women in "Other States" after 1997. The figures for the other groups are similarly constructed. The pictures for men (Panels C, E, and G of Figure A.3.1) illustrate the same point: the trends in decline in mortality rates were less pronounced for elderly men in "Highly Restricted States" compared to people in "Other States" after the IPS. For women (Panels D, F, and H of Figure A.3.1) it seems that differences between highly restricted states and other states were less pronounced (except for women aged between 65 and 74: for those living in "Highly Restricted States" mortality rates increased after the IPS, but they decreased for women in "Other States").

\section{Figure A.3.1}

\section{Panel A: Trends in Mortality Rates for Men 65+, 1993-2000}

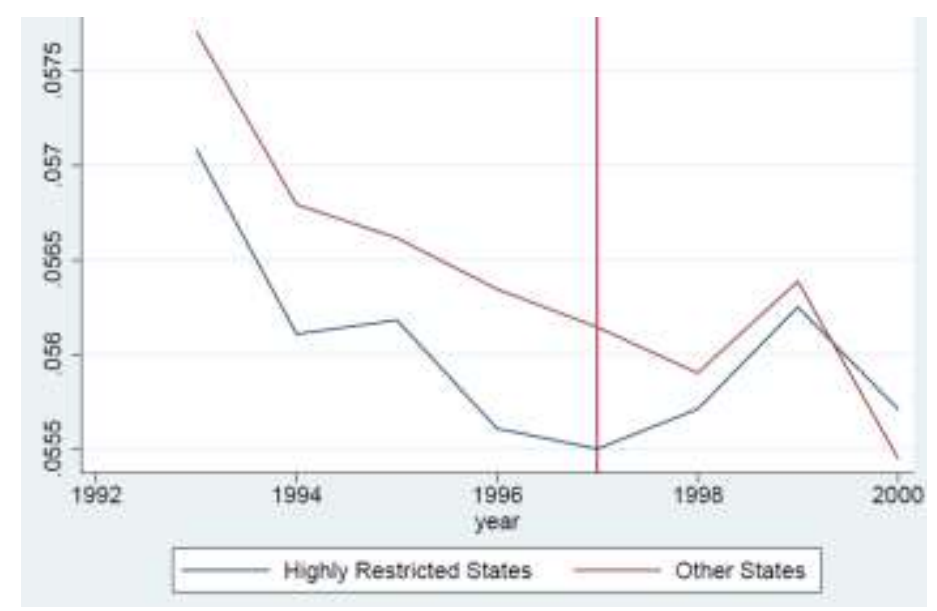


Panel B: Trends in Mortality Rates for Women 65+, 1993-2000

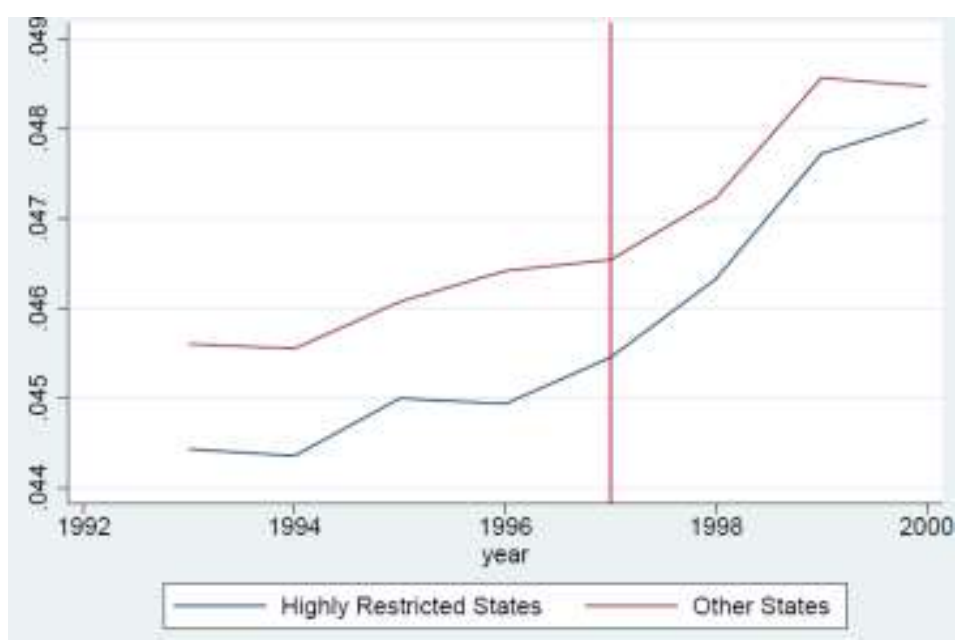

Panel C: Trends in Mortality Rates for Men 65-74, 1993-2000

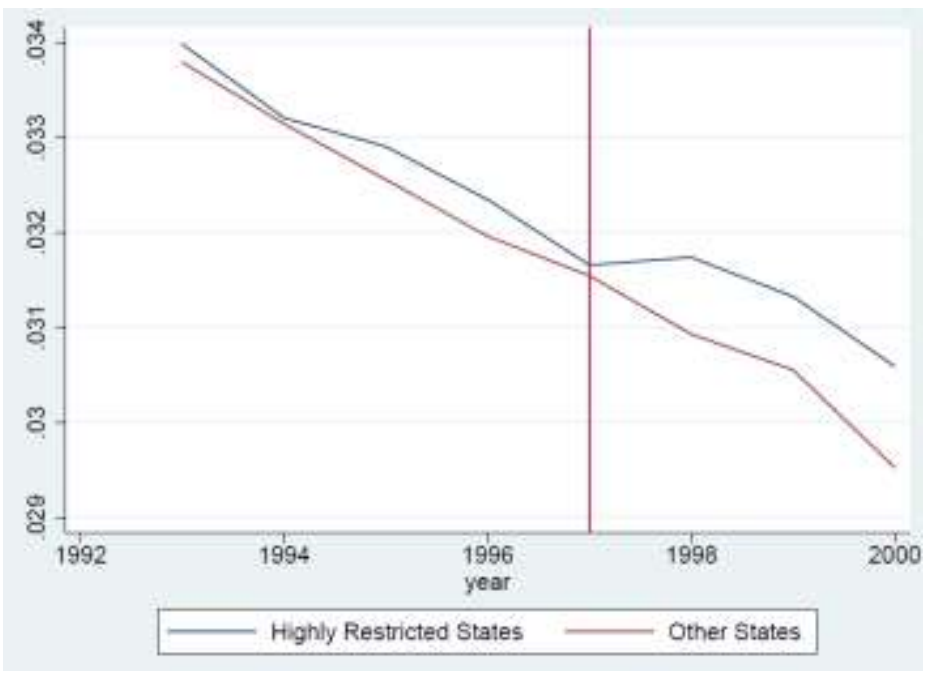


Panel D: Trends in Mortality Rates for Women 65-74, 1993-2000

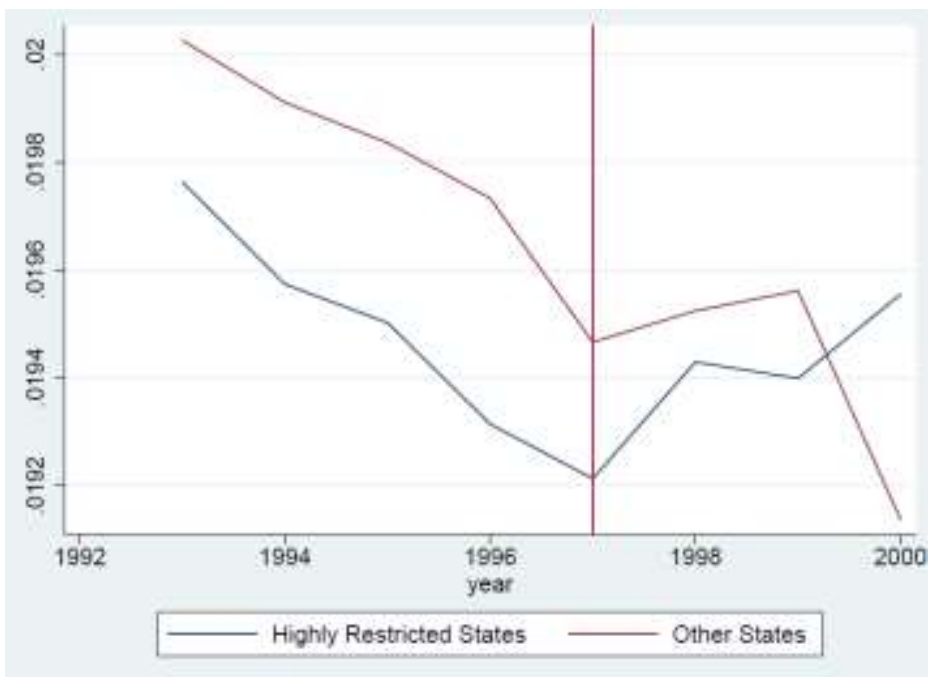

Panel E: Trends in Mortality Rates for Men 75-84, 1993-2000

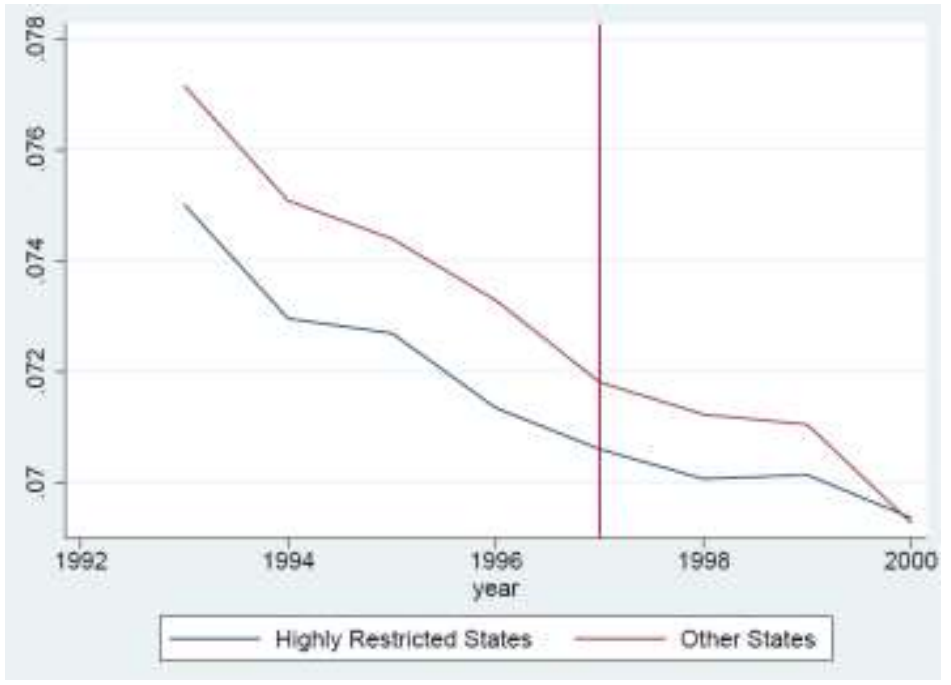

Panel F: Trends in Mortality Rates for Women 75-84, 1993-2000

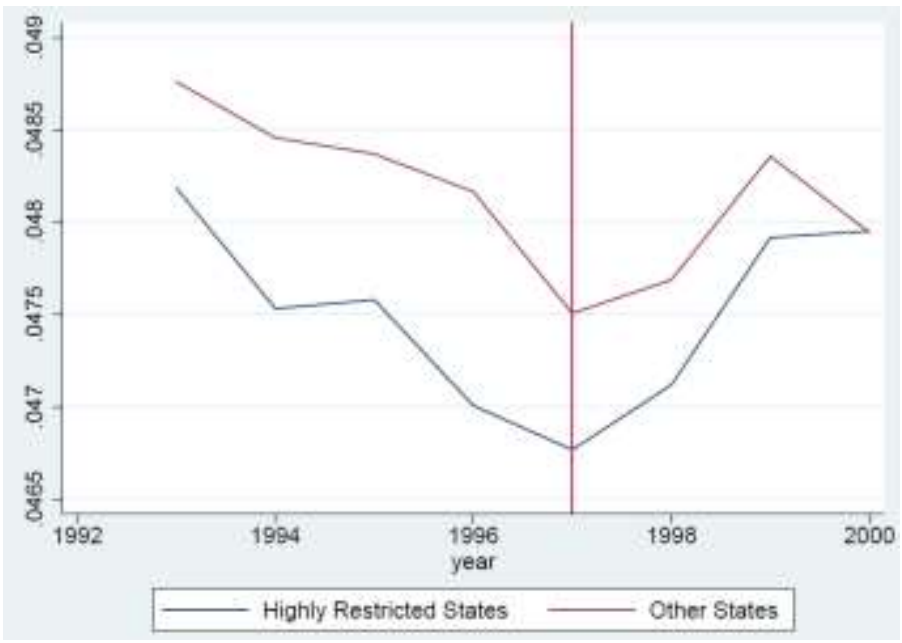


Panel G: Trends in Mortality Rates for Men 85plus, 1993-2000

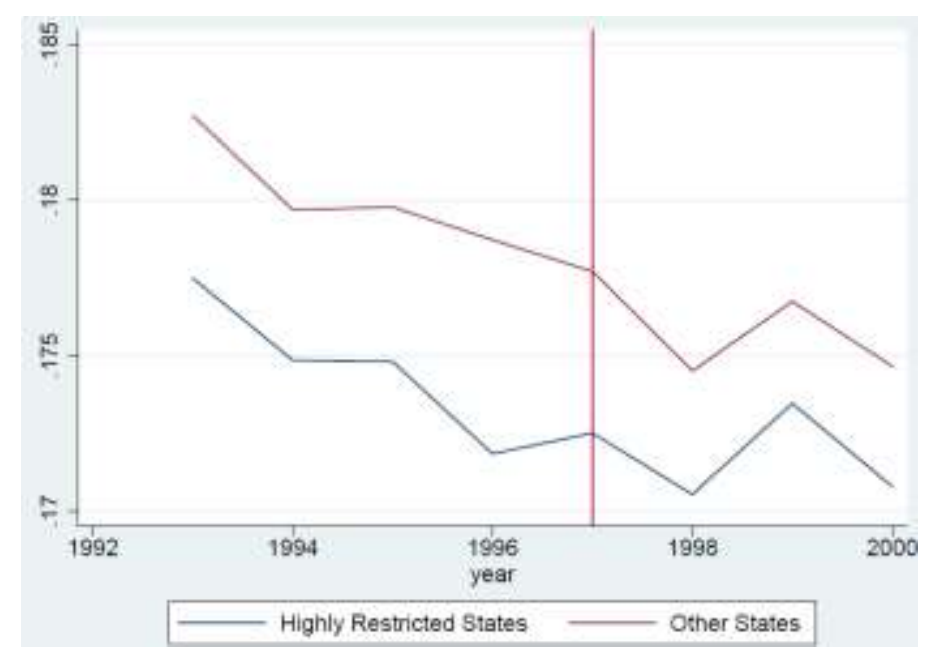

Panel H: Trends in Mortality Rates for Women 85plus, 1993-2000

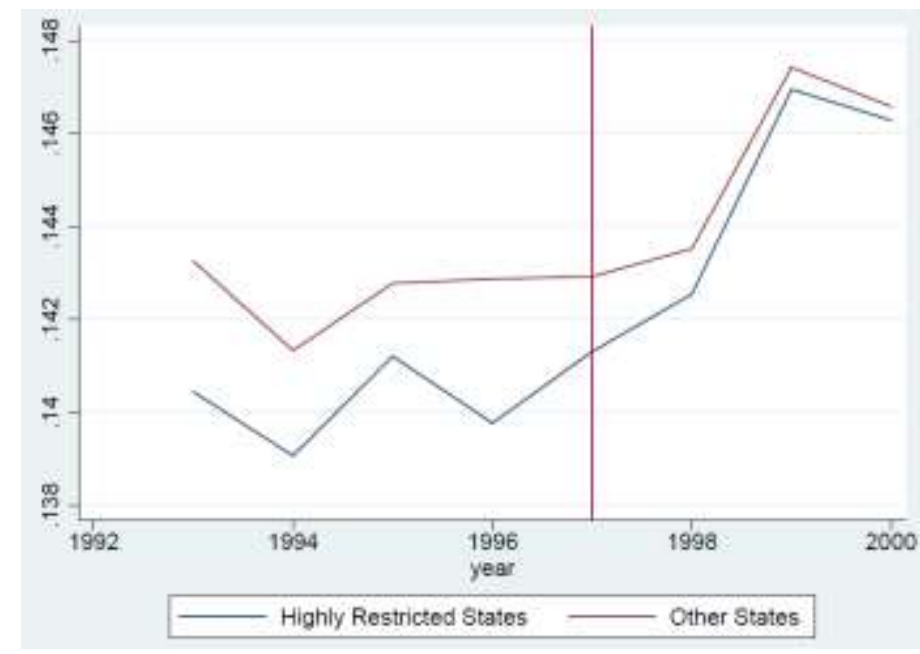

Note: the graphs above plot yearly mortality rates for men and women of various ages for states in the top $25^{\text {th }}$ percentile of the Restrictiveness Measure ("Highly Restricted States") and for states in the bottom $75^{\text {th }}$ percentile of the Restrictiveness Measure ("Other States").

Appendix 4. Percent impact on the mortality rate and impact on total deaths of cutting reimbursements by one visit per Medicare beneficiary

In this appendix I calculate the effects of a reduction of one home health visit per Medicare beneficiary on mortality rates and total deaths. From equation 2 in the main text, the estimate of $\gamma * 100$ gives the percent impact on mortality of impact of living — during the post policy period - in a state that provided an additional one visit per user above the regional (census 
division) during the pre-policy period. Given that the census division portion of the IPS payment limit was 25\%, $\gamma * 100$ can be interpreted as the percent impact on the mortality rate of cutting reimbursements by 0.25 visits per Medicare beneficiary in the post policy period; therefore, to recover the impact of cutting reimbursement of one visit, $\gamma * 100$ needs to be multiplied by 4 . Table A4.1 gives the percent impact on the mortality rate of cutting reimbursements by one visit per Medicare beneficiary in the post policy period for various groups.

It is also possible to recover the estimates of "total deaths per reduced home health visits" as explained below. Calculation of "total deaths per reduced home health visits" is presented in Table A4.2 for various groups

Recall from section 3.3 that the difference between $M_{i j 98-00 a c t u a l}$ and $M_{i j 98-00 n o ~ I P S}$ gives "deaths per decline in 3.4 visits." To recover the impact of "deaths per reduced home health visit" besides recovering (as done in the main text) $M_{i j 98-00 n o ~ I P S}$, I need to recover what I call $M_{i j 98-00}$ partial IPS, namely deaths for a "partial" IPS in which the average decline in visits per Medicare beneficiary was only 1 instead of the actual estimated 3.4.

Therefore, I need to add another step and another formula to formula 3 in the main text of the paper to find the relationship between $M_{i j 98-00 n o ~ I P S}$ and $M_{i j 98-00 \text { partial IPS }}$

The parameter estimate of $\gamma$ multiplied by 100 gives the percent impact of cutting reimbursements by 0.25 visits per Medicare beneficiary in the post policy period on the mortality rate for elderly of a given gender and age. To recover the impact on the elderly mortality rate of a decline in reimbursement of 1 visits per Medicare beneficiary $\gamma * 100$ needs to be multiplied by 4 . Therefore, I have the following relationship between $M_{i j 98-00 n o ~ I P S}$ and $M_{i j 98-00 p a r t i a l I P S}$ expressed by Equation A4.1: 
$M_{i j 98-00 n o ~ I P S}(1+4 * \gamma)=M_{i j 98-00 p a r t i a l I P S}$

The above is an equation with two unknowns, but it is possible to solve it when using the results from solving Equation 3 in the main text, which I report again for convenience below:

$$
M_{i j 98-00 n o I P S}(1+13.6 * \gamma)=M_{i j 98-00 a c t u a l}
$$

Because I know what $M_{i j 98-00 a c t u a l}$ is from actual death records between 1998 and 2000, I can use $M_{i j 98-00 a c t u a l}$ to recover $M_{i j 98-00 n o ~ I P S}$ and I can then use $M_{i j 98-00 n o ~ I P S}$ in Equation A4.1 above to recover $M_{i j 98-00 p a r t i a l I P S}$.

The actual "deaths per reduced home health visit" for each group and cause of death can be calculated as the difference between $M_{i j 98-00 p a r t i a l I P S}$ and $M_{i j 98-00 n o ~ I P S}$.

Table A4.1 Percent Change in Mortality Rates per Medicare Beneficiary Per "Reduced Home Health Visits"

\begin{tabular}{|c|c|c|}
\hline & $\begin{array}{l}\text { Men } \\
\text { (1) }\end{array}$ & $\begin{array}{l}\text { Women } \\
\text { (2) }\end{array}$ \\
\hline Age $65+$ & 0.09728 & 0.00464 \\
\hline Age $65-74$ & 0.18204 & 0.01888 \\
\hline Age $75-84$ & 0.001268 & 0.06132 \\
\hline Age $85+$ & 0.14948 & -0.05292 \\
\hline \multicolumn{3}{|c|}{$\begin{array}{l}\text { Columns } 1 \text { and } 2 \text { present estimates of } \gamma \text { in Equation } 2 \text { in the main text multiplied per } 100 * 4 \text { and represent the } \\
\text { percent change in mortality rates due to a decrease of one visit per Medicare beneficiary for different subgroups. } \\
\text { Table A4.2 Total Deaths Per "Reduced Home Health Visits" }\end{array}$} \\
\hline & $\begin{array}{l}\text { Men } \\
\text { (1) }\end{array}$ & $\begin{array}{l}\text { Women } \\
\text { (2) }\end{array}$ \\
\hline Age $65+$ & 2327 & 136 \\
\hline Age $65-74$ & 1378 & 111 \\
\hline Age $75-84$ & 13 & 652 \\
\hline Age $85+$ & 927 & -685 \\
\hline
\end{tabular}




\section{Appendix 5. FDR Correction}

I this Appendix I report a summary of the steps for implementing the FDR correction procedure proposed by BKY (2006). The description below is in large part from the summary in Anderson (2008). Since the BKY(2006) FDR correction has as a starting point Benjamini and Hochberg (1995)'s procedure, it is worth reporting how to implement this procedure first. According to Benjamini and Hochberg (1995), suppose that we are testing an M hypothesis that we call $\mathrm{H}_{1}$, $\mathrm{H}_{2, \ldots} \mathrm{H}_{\mathrm{M}}$, and order the $\mathrm{p}$-values of the hypothesis from the smallest to the largest so that $p 1<p 2$ $<\cdots<p M$. If $\mathrm{q} \in(0,1)$ and $\mathrm{c}$ is the largest $\mathrm{r}$ for which $p_{r}<q r / M$, beginning with $p M$, we check whether each p-value meets $p r<q r / M$. When one does, we reject it and all smaller p-values. Rejecting all hypotheses $\mathrm{H}_{1}, \mathrm{H}_{2}, \ldots \mathrm{H}_{\mathrm{C}}$ controls the FDR at level $q$. The procedure can be sharpened because Benjamini and Hochberg (1995)'s procedure is still conservative; because we do not know the number of the true null hypotheses, let us call this number $m 0$. If we did, we could replace $q r / M$ with $q r / m 0$, which would be advantageous because $q r / m 0>=q r / M$. The BKY (2006) two-step procedure estimates the number $m 0$ to have a sharpened FDR control compared to the one proposed by Benjamini and Hochberg (1995), from now on referred to as BH. As Anderson (2008) reports, the procedure is implemented in two steps:

1Apply the BH procedure at level $q=q /(1+q)$.

Let $c$ be the number of hypotheses rejected. If $c=0$, stop; otherwise, continue to step 2 .

2. Let $\widehat{m}_{0}=M-c$

3. Apply the BH procedure at level $q^{*}=q^{\prime} M / \widehat{m_{0}}$.

Anderson (2008) also provides a Stata do file that gives the smallest $\mathrm{q}$ at which the hypothesis under test would be rejected, calculated using the BKY (2006) procedure. This value in the 
context of correction for FDR is an analogue of the p-value. These smallest $q$ at which the hypothesis under test would be rejected are the values reported in italics in Tables 5, 6 and 7 in the revised version of the paper.

\section{References}

Benjamini, Y., and Hochberg, Y. 1995. Controlling the False Discovery Rate. Journal of the Royal Statistical Society, Ser. B, 57, 289-300.

Hoynes, H., Miller D., Simon, D. 2015. Income, the Earned Income Tax Credit, and Infant Health. American Economic Journal: Economic Policy, American Economic Association, vol. $7(1)$, pages $172-211$ 